Check for updates

Cite this: Chem. Soc. Rev., 2021, 50, 2737

Received 30th October 2020

DOI: $10.1039 / \mathrm{d} 0 \mathrm{cs} 00948 \mathrm{~b}$

rsc.li/chem-soc-rev

\section{Advances in applied supramolecular technologies}

\author{
George T. Williams, (D) a Cally J. E. Haynes, (D)*b Mohamed Fares, ${ }^{c}$ \\ Claudia Caltagirone, (D)*d Jennifer R. Hiscock (D)*a and Philip A. Gale (D)*ce
}

\begin{abstract}
Supramolecular chemistry is a comparatively young field that to date has mainly been focused on building a foundation of fundamental understanding. With much progress in this area, researchers are seeking to apply this knowledge to the development of commercially viable products. In this review we seek to outline historical and recent developments within the field of supramolecular chemistry that have made the transition from laboratory to market, and to bring to light those technologies that we believe have commercial potential. In doing so we hope we may illuminate pathways to market for research currently being conducted.
\end{abstract}

\section{Introduction}

The term supramolecular chemistry was first coined by JeanMarie Lehn in the 1970s. ${ }^{1}$ Although this was first use of the term, the study of non-covalent molecular complexation, a field that we now identify as being part of supramolecular chemistry, was already under investigation within the scope of other scientific fields such as enzymology, organic chemistry and inorganic chemistry. ${ }^{2-4}$ Today, supramolecular chemistry broadly encompasses the study of all types of intermolecular non-covalent bond formation in designed molecular systems, and also incorporates dynamic covalent chemistry. ${ }^{5-7}$ The body of work undertaken in this field since the late 1960s has twice resulted in the award of the Nobel prize in Chemistry, first in 1987 and again in 2016, for the development of host-guest binding molecules ${ }^{8}$ and molecular machines respectively. ${ }^{9}$

${ }^{a}$ School of Physical Sciences, University of Kent, Canterbury, Kent, CT2 7NH, UK. E-mail: j.r.hiscock@kent.ac.uk

${ }^{b}$ Department of Chemistry, UCL, London, WC1H OAJ, UK. E-mail: cally.haynes@ucl.ac.uk

${ }^{c}$ School of Chemistry, The University of Sydney, Sydney, NSW 2006, Australia.E-mail: philip.gale@sydney.edu.au

${ }^{d}$ Dipartimento di Scienze Chimiche e Geologiche, Università degli Studi di Cagliari, S.S. 554 Bivio per Sestu, 09042 Monserrato (CA), Italy. E-mail: ccaltagirone@unica.it

${ }^{e}$ The University of Sydney Nano Institute (Sydney Nano), The University of Sydney, NSW 2006, Australia

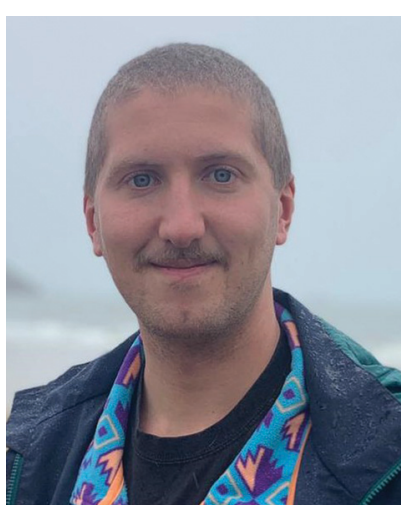

George T. Williams
George Williams is a postdoctoral research fellow at the University of Kent in the group of Dr Jennifer Hiscock. He completed his undergraduate studies and PhD at the University of Bath under the supervision of Prof. Toby Jenkins. His research primarily focusses around the use of supramolecular chemistry to develop sensors, drug delivery vehicles and stimuli responsive materials.

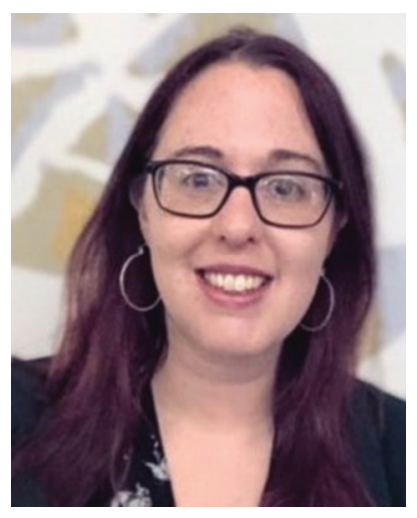

Cally J. E. Haynes

Cally Haynes is a Lecturer in Organic Chemistry and Chemical Biology at UCL. She studied for a PhD in the group of Prof. Phil Gale at the University of Southampton and carried out postdoctoral research in the same group until 2013. Following an editorial position with the Royal Society of Chemistry, she joined the research group of Prof. Jonathan Nitschke at the University of Cambridge as a postdoctoral researcher in 2015 before joining UCL in 2019. Her research interests in supramolecular chemistry include molecular transport and separations, coordination driven self-assembly and the design of functional soft materials. 
As a rapidly growing scientific field of study, supramolecular chemistry is now expanding beyond the chemical space, finding applications at the interfaces with many other disciplines, and offering novel solutions to age old problems in biology, physics, engineering and pharmacy. ${ }^{10}$ This has caused the field of supramolecular chemistry to move towards commercial, real world applications whilst fundamental studies still continue. As a result industry has now begun to embrace this field of chemistry, incorporating aspects of these next generation technologies into a variety of everyday commercial, marketable products. ${ }^{7,11-13}$

Examples of applied supramolecular innovation include the development of medical diagnostic sensors, enabled through advances in selective host-guest complex formation; ${ }^{7,14}$ maintenance free materials, created through incorporation of reversible non-covalent moieties within material constructs; ${ }^{15,16}$ and ion extraction realised through the development of molecular encapsulation technologies. ${ }^{17,18}$ Herein, we update and expand on a previous review by Kolesnichnko and Anslyn, ${ }^{19}$ to discuss the application of supramolecular chemistry in the real world. This includes commercial examples of supramolecular chemistry in everyday items, sensors, medicine, materials and extraction technologies. Additionally, we provide insight into recent supramolecular developments that may have the potential to make the transition from laboratory to market.

\section{Supramolecular chemistry in the household}

Supramolecular chemistry underpins the workings of many products and, perhaps surprisingly, many of these are simple household items. An example of these items are the cyanoacrylate adhesives, more commonly known as superglue. The late M. Anthony McKervey and his group at Queen's University, Belfast were calixarene chemists who reported (in collaboration

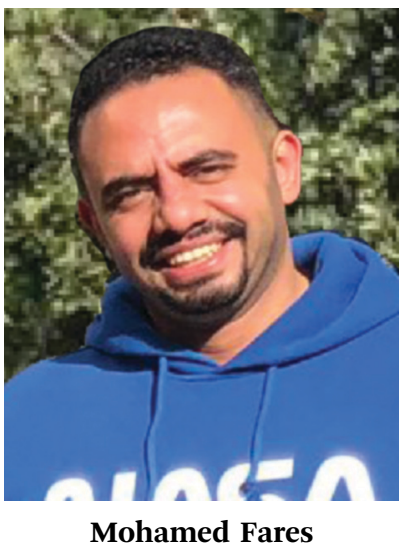

Mohamed Fares is a postdoctoral researcher at the School of Chemistry, University of Sydney (Gale group). After finishing BPharm (Ain Shams University, Egypt) and MPharm (Cairo University, Egypt), he was awarded the prestigious IPRS in 2015 to pursue his $P h D$ at the University of Wollongong (Australia) under supervision of Professor Paul Keller and Professor Phil Gale. Mohamed's research interests include the anion transport supramolecular chemistry and small molecule drug discovery.

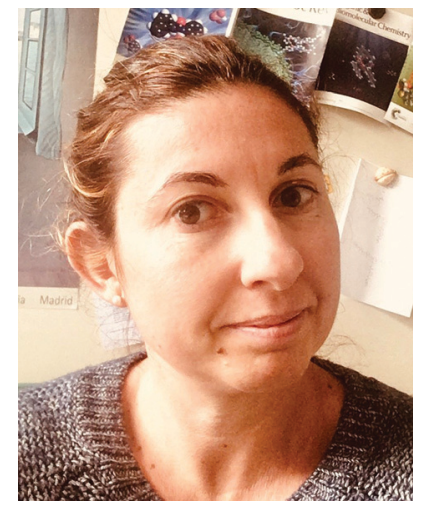

Claudia Caltagirone
Claudia Caltagirone obtained her $P h D$ in Chemistry under the supervision of Prof. Vito Lippolis at the University of Cagliari (Italy) in 2006. In the same year she became assistant professor in Inorganic Chemistry and then she moved to the University of Southampton (UK) to work as an academic visitor in the group of Prof. Philip A. Gale. Since 2016 she is associate professor in Inorganic Chemistry at the University of Cagliari. Her research mainly focuses on the design of novel supramolecular systems for anion sensing and for the development of new materials.

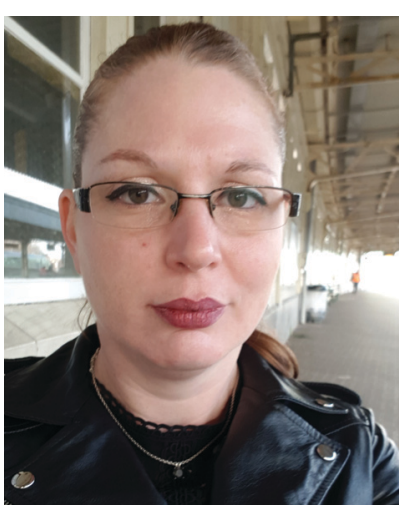

Jennifer R. Hiscock
Jennifer Hiscock is a Reader in Supramolecular Chemistry, Director of Innovation and Enterprise and UKRI Future Leaders Research Fellow in the School of Physical Sciences at the University of Kent (UK). She studied for a PhD in the group of Prof. Phil Gale at the University of Southampton and carried out postdoctoral research in the same group until 2015. Following this she moved to the University of Kent as the Caldin Research Fellow and was appointed Lecturer in Chemistry at this same institution in 2016. Her current research interests focus on the development of Supramolecular Self-associating Amphiphiles (SSAs) as antimicrobial, anticancer and drug adjuvant agents.

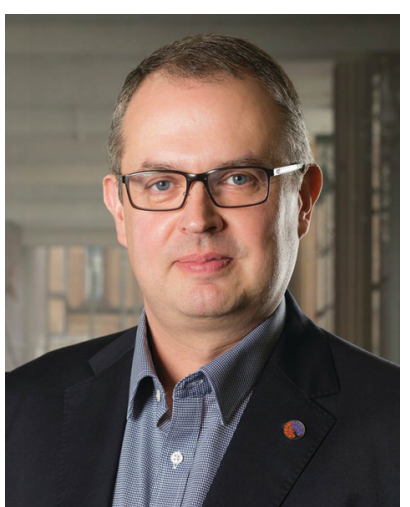

Philip A. Gale
Phil Gale is Professor and Head of the School (Chemistry), and Associate Dean (International) in the Faculty of Science at the University of Sydney. Phil's research interests focus on the supramolecular chemistry of anionic species and in particular the molecular recognition, sensing and lipid bilayer transport of anions. His research group's contributions to these areas were recognized in 2018 by the International Izatt-Christensen Award in Macrocyclic and Supramolecular Chemistry. 
with Schwing-Weill and co-workers) a number of ionophoric calix $[n]$ arenes formed by appending additional groups to the lower-rim. For example, $p$-tert-butylcalix $[n]$ arene where $n=4$ or 6 could be reacted with ethyl bromoacetate in dry acetone in the presence of potassium carbonate as base by refluxing for several days to afford the calix[4]arene tetra-ester $\mathbf{1}$ or calix[6]arene hexa-ester 2 respectively. ${ }^{20}$ These compounds have high affinities for group 1 metal cations with compound 1 showing $\mathrm{Na}^{+}$selectivity over other group 1 metal cations whilst compound 2 is selective for larger metal cations. McKervey and co-inventors found that these types of ionophoric calixarenes could be used in super glue as accelerators by sequestering group 1 metal cations. For example, the addition of $0.1 \%$ compound 2 to a commercially available cyanoacrylate-based adhesive reduced fixture time from between 20 to 25 minutes to between 3 and 5 minutes, allowing porous surfaces to be effectively bonded together before the glue had diffused away (Fig. 1). ${ }^{21}$

Another class of supermolecular host used as components of household products are the cyclodextrins (CDs), which are cyclic oligosaccharides that consist of glucose monomers linked by $\alpha-1,4$-glycosidic bonds. ${ }^{22}$ These compounds were first isolated by Antoine Villiers in 1891 and are produced from starch by an enzymatic degradation process. ${ }^{22,23}$ Another household use of supramolecular chemistry is in the product Febreze which is manufactured by Procter and Gamble. Febreze is a spray that eliminates household odours and can be used on fabrics. ${ }^{11}$ The spray contains hydroxypropyl beta-cyclodextrin (HPBCD) (3), a cyclodextrin derivative with increased solubility. In this case 3 is reputed to complex odour molecules within the cavity of the macrocycle and so suppresses odours. HPBCD as a mixture of compounds with various degrees and patterns of
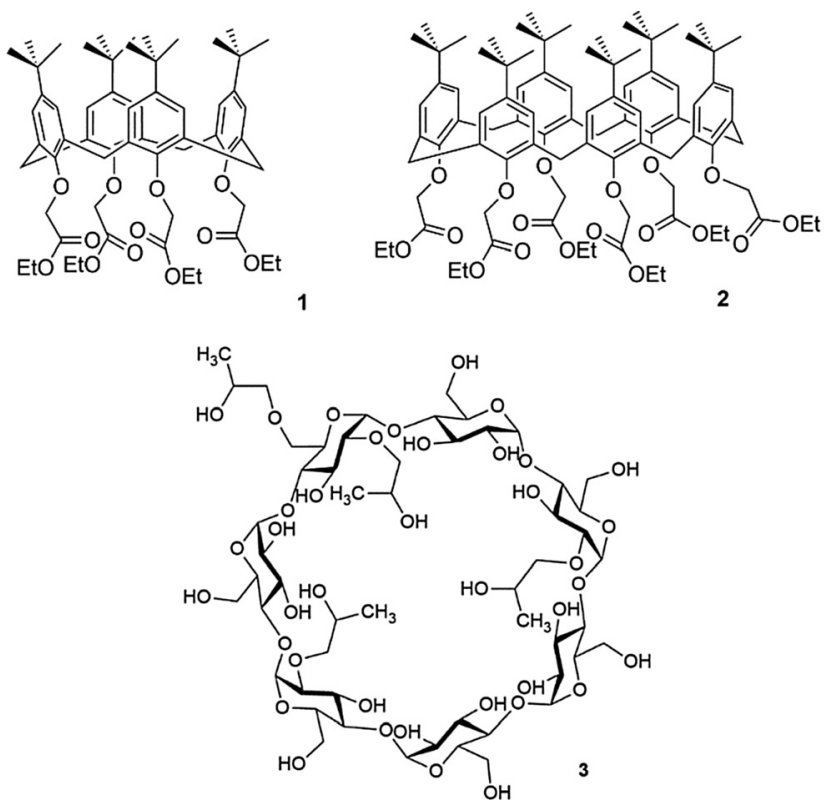

Fig. 1 Calix[4]arene tetra-ester (1) and calix[6]arene hexa-ester (2) which have found use in superglue formulation, and hydroxypropyl betacyclodextrin (3), an odour trapping molecule found in Febreze. hydroxypropylation and along with other cyclodextrin derivatives has been used as an excipient to improve the water solubility and bioavailability of drugs. ${ }^{24}$

\section{Supramolecular chemistry in medicine}

The three parent cyclodextrins, $\alpha(4), \beta(5)$ and $\gamma$-CDs (6) are formed from 6, 7 and 8 D-glucose units, respectively (Fig. 2). ${ }^{25}$ Synthetic CD derivatives include the hydrophilic HPBCD, the hydrophobic 2,6-di-O-ethyl- $\beta$-CD and the ionizable sulfobutylether- $\beta$-CD. ${ }^{26}$ The approximate dimensions of $\alpha, \beta$ and $\gamma$-CDs are illustrated in Fig. 3. ${ }^{22}$ Cyclodextrins have a doughnut shaped structure with a hydrophobic cavity and a hydrophilic outer surface (Fig. 4), allowing them to accommodate small hydrophobic drugs or moieties inside the cavity. ${ }^{27}$

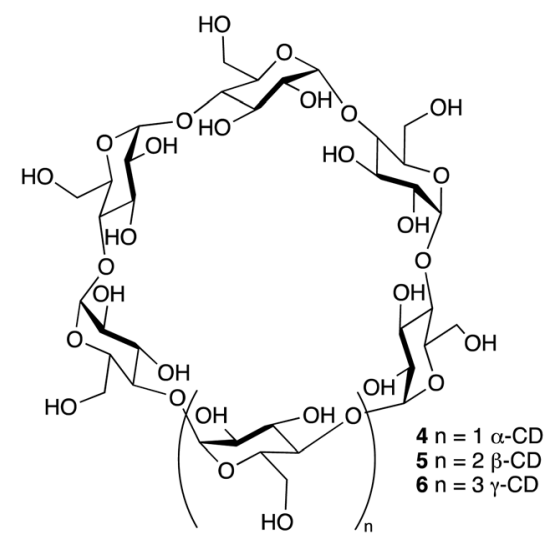

Fig. 2 Chemical structure of $\alpha, \beta$ and $\gamma$-cyclodextrin. (a)

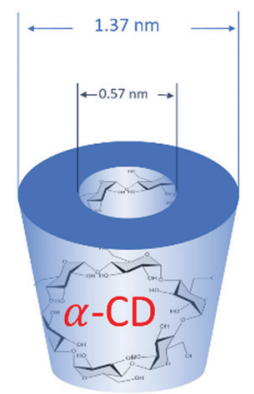

(c)

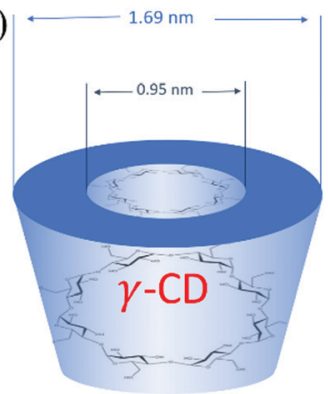

(b)

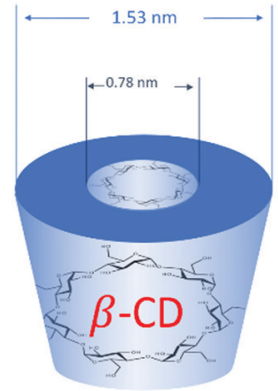

(d)

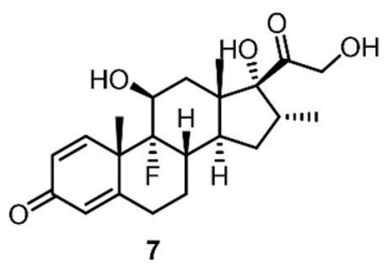

Fig. 3 (a-c) Geometric dimensions of $\alpha, \beta$ and $\gamma$-cyclodextrin, (d) structure of dexamethasone, 7 . 

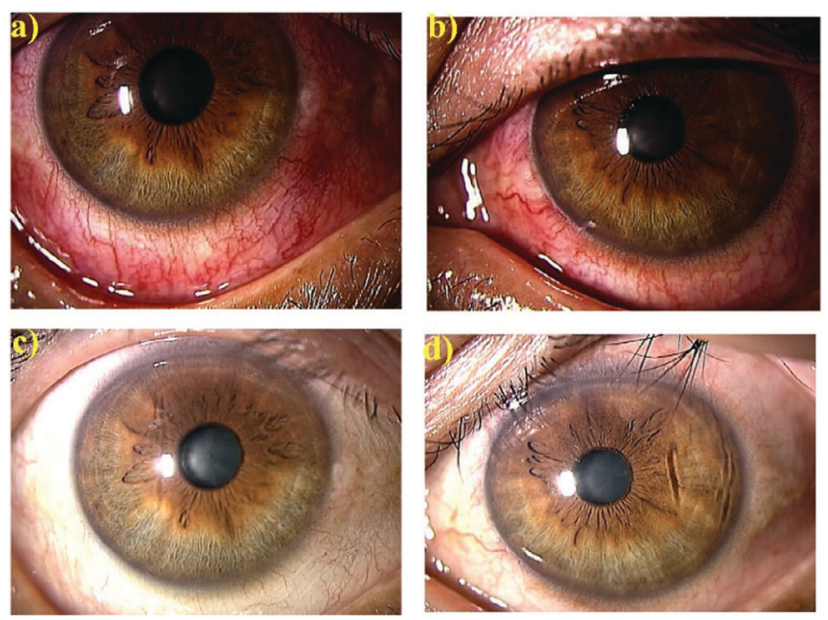

Fig. 4 Anteriorocular photographs of a 45-year-old man with anterior scleritis before ( $a$ and $b$ ) and after 4 weeks treatment with OCS-01 ( $c$ and d). Right eye ( $a$ and $c$ ) and left eye ( $b$ and $d) .{ }^{35}$ Reproduced from ref. 35 with permission from Wiley, copyright 2019.

The scalable synthesis of the parent $\alpha, \beta$ and $\gamma$-CDs also makes this scaffold a commercially attractive prospect with a comparatively low price point and ease of purification. The 30 year development in CD related technologies has led to wide applications in pharmaceuticals, drug delivery systems, cosmetics, and the food and chemical industries. ${ }^{26,28-30}$ Amongst notable applications of CDs are their use in overcoming the limitations of certain pharmaceutical compounds by forming an inclusion complex, enhancing the drug solubility and stability and improving drug permeation and bioavailability. ${ }^{22,26}$ These inclusion complexes enhance the physicochemical characteristics of the drugs without changing their intrinsic properties. However, the limitations of CDs include the small cavity size of $\alpha-\mathrm{CD}$, the low water solubility of $\beta-\mathrm{CD}$ and low production yields of $\gamma-\mathrm{CD} .^{27}$

Interestingly, a topical drug delivery system (eye drops) based on dexamethasone 7 (Fig. 3(d)) and $\gamma$-CD nanoparticles has been developed by Oculis ${ }^{\circledR} .{ }^{31}$ This non-invasive system contains $1.5 \%$ dexamethasone and $\gamma$-CD nanoparticles (OSC-01) and showed a promising reduction of the central macular thickness (CMT) and an increase in visual acuity in diabetic macular oedema (DMO) patients. ${ }^{32}$ In vivo studies in humans showed that OCS-01 achieved a 10 times higher concentration of dexamethasone in the eye tissue after $4 \mathrm{~h}$ of application, when compared to Maxidex ${ }^{\circledR}(0.1 \%$ dexamethasone only eye drops). This was mainly due to the higher ocular absorption and a longer retention of the $\gamma$-CD-drug nanoparticles at the site of action. ${ }^{33}$ OCS-01 completed phase-2 clinical trials (DX-216) for treating inflammation and pain following cataract surgery. ${ }^{34}$ Of the 144 randomized patients who started this study, 131 completed the trial. Results from DX-211 showed the efficacy of OSC-01 in patients with DME when compared to the vehicle. OCS-01 showed no significant or unexpected ocular adverse effects. ${ }^{34}$

The OCS-01 eye drops were also investigated for their antiinflammatory effect in 10 human eyes for six patients (five female) complaining of different ocular inflammatory diseases, including anterior scleritis, posterior scleritis, unidentified uveitis, Vogt-Koyanagi-Harada disease with papillitis and cystoid macular oedema. ${ }^{35}$ All treated eyes responded to OCS-01 with a rapid resolution of congestion with no patients experiencing impaired visual acuity after the treatment started. ${ }^{35}$ Fig. 4 shows both eyes of a 45 -year-old man with anterior scleritis before (Fig. 4(a and b)) and after 4 weeks treatment with OCS-01 (Fig. 4(c and d)). After treatment, ocular congestion almost disappeared, and the pain was reduced significantly and did not recur. ${ }^{35}$

Poor control of blood glucose levels is implicated with increased morbidity and mortality, especially in hospital intensive care unit (ICU) patients. ${ }^{36,37}$ Continuous glucose monitoring over a $24 \mathrm{~h}$ period is useful when seeking to acquire control of blood sugar and to avoid hypo- and hyper-glycaemia, especially in diabetic patients. ${ }^{38,39}$ Great efforts have been made in the development of D-glucose sensors based on supramolecular interactions between boronic acid motifs and sugars via hydrogen bonding and ester formation. ${ }^{40-44}$ Boronic acids are a reliable group for sugar sensing and have showed a high affinity for vicinal diols, catechols and compounds appended with $\alpha$-hydroxycarboxylate when incorporated into different scaffolds. ${ }^{44}$ However phenylboronic acid shows significant binding to carbohydrates only above physiological $\mathrm{pH}$, indicating its limited application. ${ }^{41,45}$ The inclusion of an $\alpha$-aminomethyl group in the ortho-position of the boronic acid was found to tune the selectivity and improve the binding affinity at neutral $\mathrm{pH}^{46-49}$ Interestingly, mono or simple boronic acids have been found to bind to saccharides in the order D-fructose $>$ D-galactose $>$ D-mannose $>$ D-glucose. ${ }^{50-52}$ Changing the binding site to a diboronic acid motif and expanding the structure into more complex systems, capable of binding at multiple sites, perturbed the D-glucose selectivity. ${ }^{51}$ Finally, incorporating fluorophores such as pyrene and anthracene into the $\alpha$-aminomethylphenylboronic acid scaffold has yielded hosts that have been used for sensing and cellular imaging. ${ }^{44,52}$

As a result of these innovations, two companies, namely Eversense (by Senseonics) and Glysure Ltd, have been founded by Tony James and his collaborators, exploiting the application of fluorescent $o$-aminomethylphenylboronic acids, (8) (Fig. 5). ${ }^{53-55}$ The Glysure system (9, Fig. 6(a)) and the Eversense (10, Fig. 6(b))

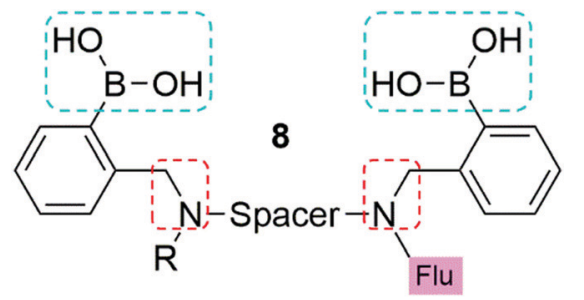

Fig. 5 The general structure of the boronic acid based glucose sensors used for continuous glucose monitoring. Blue boxes outline the two boronic acids used to give $\mathrm{D}$-glucose selectivity. Red boxes indicate the ortho $\alpha$-amino acid to improve saccharide binding affinity at neutral $\mathrm{pH}$. $\mathrm{R}$ represents the anchor point to a hydrogel, for example poly(2hydroxyethylmethacrylate). A six carbon chain is used as the spacer to give glucose selectivity, and may be aliphatic (Glysure LTD) or aromatic (Eversense) in nature. 

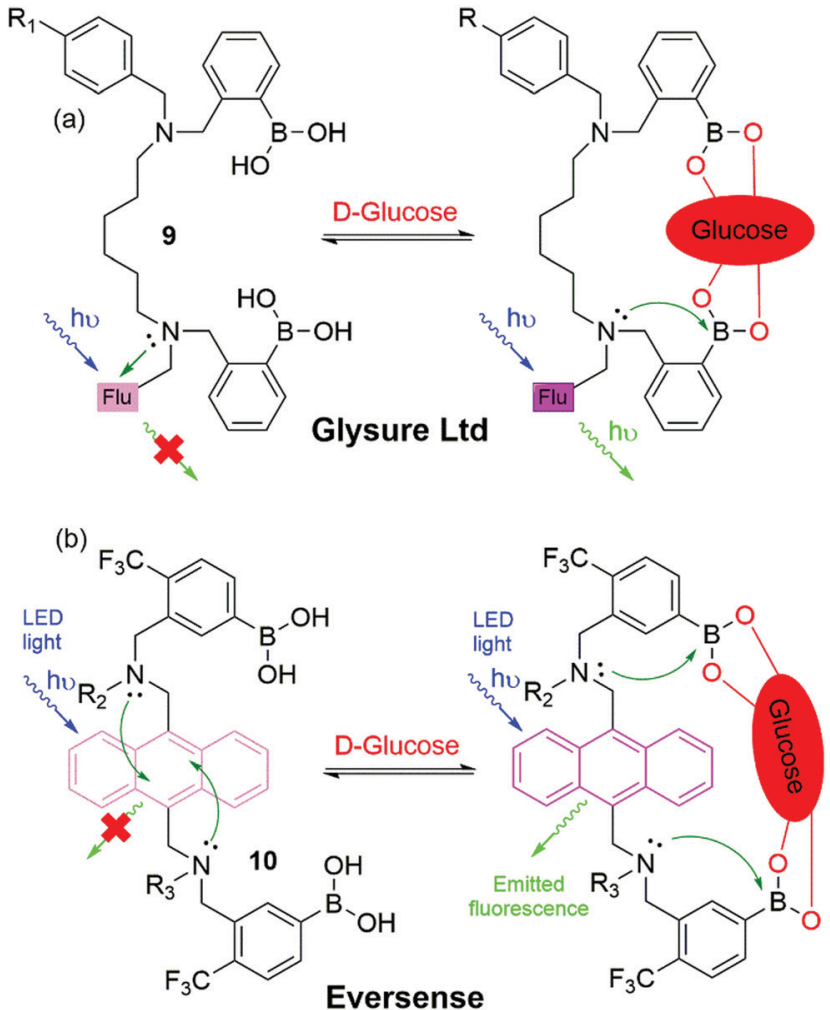

Fig. 6 Chemical structure and proposed glucose binding mode of (a) the Glysure Ltd system $9\left(R_{1}=\right.$ hydrogel) and (b) the Eversense system $10\left(R_{2}=\right.$ propionic acid side chain, $R_{3}=$ hydrogel).

detection chemistry are based on the covalent interaction between the diboronic acids motifs and D-glucose and the formation of cis-1,2-diols or 1,3-diols resulting in the formation of either a five or six membered ring system..$^{54}$ The acidity of the boron atoms increases when D-glucose binds to the boronic acid groups leading to the formation of weak boron-nitrogen $\left(\mathrm{B}^{\wedge} \mathrm{N}\right)$ bonds. The $\mathrm{B}^{\wedge} \mathrm{N}$ interaction disrupts electron transfer from the tertiary amines to covalently tethered fluorophores thus leading to fluorescence emission..$^{54}$ The resulting fluorescence is proportional and quantitative to the $\mathrm{D}$-glucose concentration. Both systems demonstrated a valid and accurate continuous monitoring of blood glucose levels, receiving CE Mark approval in 2015 (Glysure) (Fig. 6(a)) and 2017 (Eversense) (Fig. 6(b)). The Eversense system is derived from the unprecedentedly selective glucose chemosensor (10) developed by James, Sandanayake and Shinkai in 1994, while Glysure system (9) is based on the fluorescent sensor discovered by Arimori, Frimat and James in 2001 as part of a collaboration with Beckman Coulter. ${ }^{51-53,56,57}$

Blood glucose monitoring devices incorporating the Glysure and Eversense systems are illustrated in Fig. 7. The Glysure system shown in Fig. 6(a) is immobilized within a hydrogel, while the Eversense system (Fig. 6(b)) is immobilized in a poly(2-hydroxyethylmethacrylate) (pHEMA) hydrogel which is copolymerized with a fluorescent indicator. ${ }^{54}$ The Glysure sensor device is composed of the immobilized fluorescent glucose indicator cell, (Fig. 7(a))..$^{54}$ The immobilized hydrogel fills the optical fibre which is surrounded by a dialysis membrane, and consequently fills the optical cell. The microporous membrane, with a pore diameter $\sim 0.1 \mu \mathrm{M}$, prevents blood cells from entering the sensor (Fig. $7(\mathrm{a})) .{ }^{54}$

The subcutaneous Eversense sensor monitors glucose concentration in interstitial fluids (Fig. $7\left(\right.$ b)). ${ }^{58}$ This sensor has a diameter of $3.3 \mathrm{~mm}$ and a length of $15 \mathrm{~mm}$, which is then enclosed in a rigid and biocompatible polymer capsule (Fig. 7(b)). ${ }^{58}$ The glucose detection hydrogel is copolymerized onto the capsule surface, while a light emitting diode (LED) provides the excitation source for the fluorescent gel. Two filtered photodiodes measure the fluorescence intensity, while the antenna is responsible for communication with the transmitter.

An externally worn device communicates with the inserted sensor and receives the recorded information. The measurements can also be displayed on a secondary output wirelessly via Bluetooth ${ }^{\mathrm{TM}}$ and can be downloaded through a Universal Serial Bus (USB) port (Fig. 7(b))..$^{53}$

Cucurbiturils (CB) are synthetic barrel-shaped macrocycles obtained from the condensation of formaldehyde and glycolurils. ${ }^{59,60}$ Although first synthesized more than 100 years ago, cucurbit[6]uril (CB[6]), 11, shown in Fig. 8, was only characterized in the $1980 \mathrm{~s} .{ }^{59}$ Over the last two decades, other members of the $\mathrm{CB}$ family have been synthesized and purified, including $\mathrm{CB}[5], \mathrm{CB}[7], \mathrm{CB}[8]$, and $\mathrm{CB}[10]$ containing $5,7,8$, or 10 glycoluril subunits, respectively. ${ }^{60,61}$ CBs display unique physical, chemical and biological properties, primarily owing to their intrinsic ability to undergo complexation with diverse chemical species resulting in the formation of dynamic hostguest complexes. Recently, CBs have gained interest within an increasingly diverse range of applications including nanotechnology, molecular recognition, catalysis, drug delivery, analytical and environmental chemistry and chemical biology. ${ }^{60-64}$ For example, $\mathrm{CB}[7]$ typically binds one guest molecule and can be crosslinked with a variety of motifs, such as adamantane and gold nanoparticles, to prepare supramolecular hydrogels, functional surfaces and nanoparticles with commercial applications. ${ }^{65,66}$

A recent study in this area has employed $\mathrm{CB}[7]$ as a noncovalent linker motif to enhance the interaction between catechol functionalized chitosan (CAT-CS) and superparamagnetic $\gamma-\mathrm{Fe}_{2} \mathrm{O}_{3}$ nanoparticles. ${ }^{67}$ Fig. 9 shows the synthesis of a magnetic hydrogel nanocomposite composed of $\mathrm{CB}[7]$ linked to superparamagnetic $\gamma-\mathrm{Fe}_{2} \mathrm{O}_{3}$ nanoparticles, bound to the CAT-CS polymer backbone. Here the polysaccharide chitosan is post-functionalized with the catechol motif yielding CAT-CS, which was is then complexed with $\mathrm{CB}$ [7] via inclusion of the catechol side chains in the cavities of the $\mathrm{CB}[7]$ macrocycles. The carbonyl groups of the $\mathrm{CB}[7]$ then bind with the $\gamma-\mathrm{Fe}_{2} \mathrm{O}_{3}$ nanoparticles through electrostatic interactions, resulting in the formation of a noncovalent network (Fig. 9). The hybrid supramolecular hydrogel (HSH) displays heat generation through vibrational movement upon exposure to an alternating magnetic field. This offers a promising stimuli-responsive thermochemotherapy, which has been investigated for biological activity both in vitro and in vivo.$^{67}$ Here, in vitro cellular thermal studies 
(a)

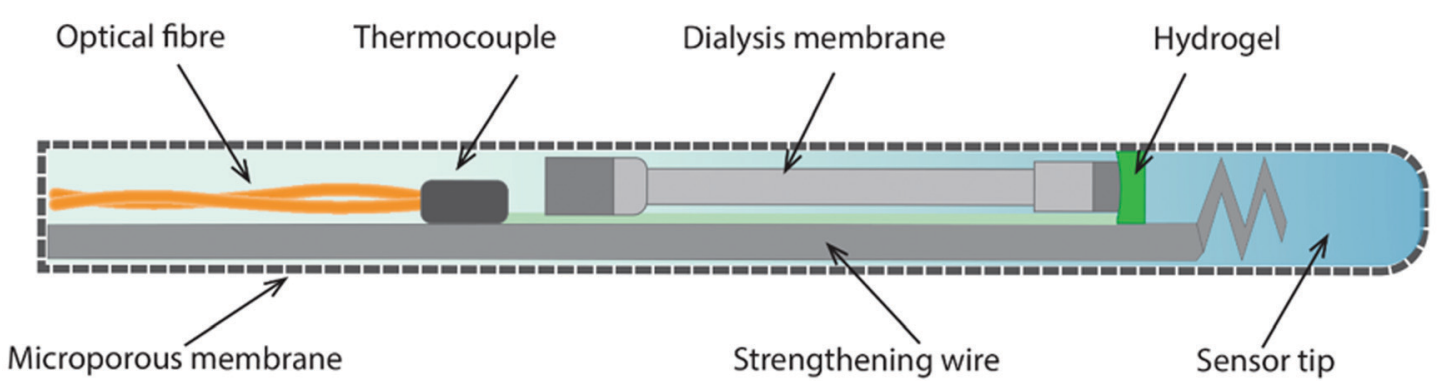

(b)

\section{$20 \mathrm{~mm}$}

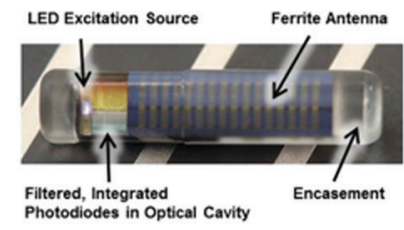

Cross section of the sensor

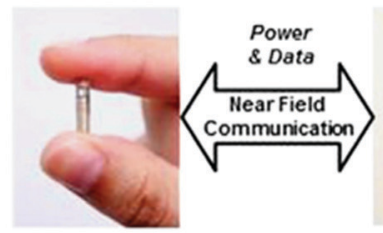

Sensor (subcutaneous)

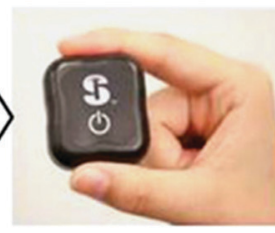

Wearable Transmitter

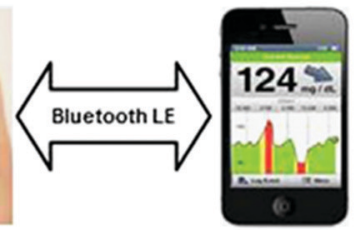

Mobile Medical App (on a Smartphone)

Fig. 7 Continuous glucose monitoring system components of (a) Glysure Ltd and (b) Eversense, reproduced from ref. 53 with permission from Elsevier, copyright 2014.

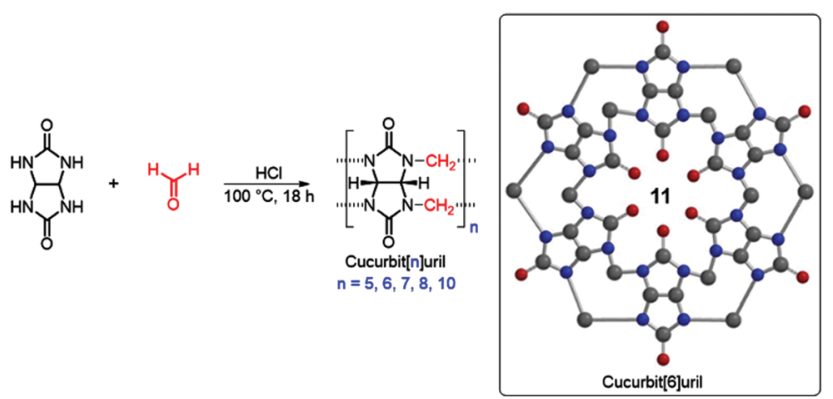

Fig. 8 Standard synthesis of $\mathrm{CB}[n]$ and $2 \mathrm{D}$ chemical structure of $\mathrm{CB}[6] 11$

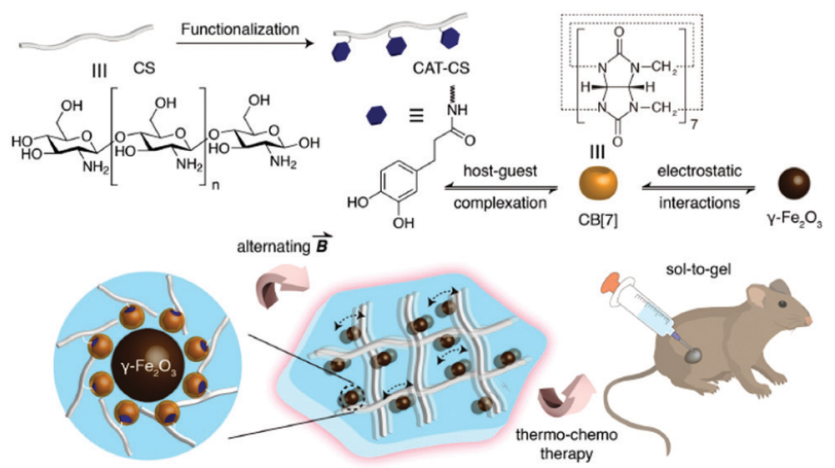

Fig. 9 Schematic representation of the hybrid supramolecular hydrogel (HSH) fabrication via CB[7]-mediated electrostatic interactions molecular recognition. ${ }^{67}$ Reproduced from ref. 67 with permission from Wiley, copyright 2019.

conducted using the apoptosis detection kit annexin V-FITC/PI in HeLa cells, showed that when the HSH was exposed to an alternating magnetic field for 12 minutes, cell apoptosis was induced through an increase in temperature. ${ }^{67}$ Additionally, comparative in vivo intravital fluorescence imaging and infrared thermography studies were performed in tumour-bearing nude mice. In this study, mice were injected with indocyanine greenloaded HSH and, it was shown that in the presence of alternating magnetic pulses tumour size decreased. These effects were shown to be dependent on exposure time, with longer exposures leading to a greater reduction in tumour size (Fig. 10(a-c)). This indicates that the intermittent exposure to magnetic pulses was the major contributing factor to both the therapeutic outcomes and overall mouse fitness, as indicated by comparative difference in mouse body weight. Finally, hematoxylin and eosin (H\&E) staining and the immunohistochemical examination of biomarkers for cell proliferation and apoptosis were also performed (Fig. 10(d)). These results showed that in this instance thermoand chemotherapies were acting synergistically, while the immunohistochemical examinations suggested that the intermittent magnetic irradiation provided an efficient way to suppress tumour growth in vivo. ${ }^{67}$

\section{Supramolecular sensors}

Since the pioneering work of Czarnick and de Silva reported in the 1980's and early 1990's, relating to the development of molecular chemosensors, ${ }^{68-74}$ numerous papers have appeared in the literature on the subject. Quite surprisingly, only a few systems have found application in real life so far. The company Optimedical Inc. commercialised a medical diagnostic analyzer (OPTI LION ${ }^{\circledR}$ ) based on three molecular fluorescent chemosensors 12-14, (Fig. 11), selective for $\mathrm{Na}^{+}, \mathrm{K}^{+}$, and $\mathrm{Ca}^{2+}$, respectively, designed by de Silva and collaborators. This device can 
(a)

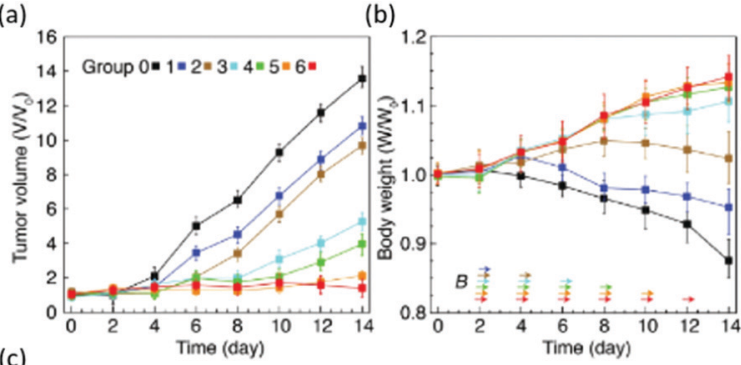

(c)

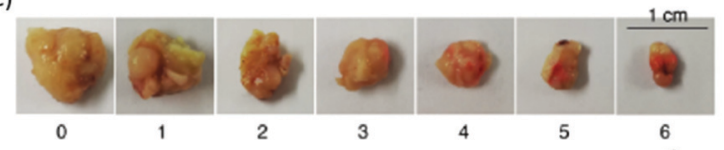

(d)

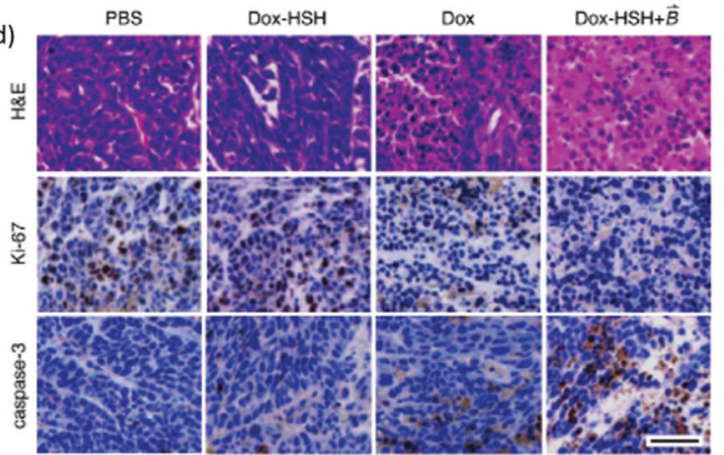

Fig. 10 Changes in (a) tumour volume (b) and body weight within 14 days of treatment, arrows indicate the time when the magnetic field was applied. (c) Images of tumors isolated at the end of the experiment. (d) (H\&E staining) and immunohistochemical (Ki-67 for cell proliferation and cleaved caspase-3 for apoptosis) analysis was performed on HeLa tumour tissues in mice treated with PBS buffer (control), Dox-loaded HSH (absences of the magnetic field), Dox (presence of the magnetic field), Dox-loaded HSH (presence of the magnetic field), Scale bar is $50 \mu \mathrm{m}^{67}$ Reproduced from ref. 67 with permission from Wiley, copyright 2019.

quantify the concentrations of electrolytes contained within blood serum via fluorescence measurements. This system is currently marketed for use within hospital critical care units, ambulances, and even in veterinary settings. ${ }^{75,76}$

Additionally, a spin-out company from the University of Bristol, UK, Zylo, founded by Anthony Davis and focused on the development of biomimetic glucose binding molecules was acquired by the global healthcare company Novo Nordisk in 2018. Davis and co-workers are still working in the field, in a new company named Carbometics, and have recently described a highly selective synthetic receptor able to bind glucose in water with a remarkable $K_{\mathrm{a}}=18000 \mathrm{M}^{-1}$, comparable with natural receptor systems. ${ }^{77}$ This lectin mimic features a highly polar hexaurea core that form hydrogen bonds with the hydroxyl groups within glucose, and a triethylmesitylene moieties that form hydrophobic/CH- $\pi$ interactions with the $\mathrm{CH}$ groups, while the high solubility in water is guaranteed by three peripheral nonacarboxylate groups. This rational design towards binding saccharides with equatorial all equatorial hydroxyls enables this lectin mimic to bind glucose over mannose, a related sugar differing by only a single axial hydroxyl group, with a 100 fold increased binding affinity $\left(K_{\mathrm{a}}=18600\right.$ and $140 \mathrm{M}^{-1}$ respectively). The system also showed high thermal stability and no toxicity towards HeLa cells. This specificity towards glucose in biological mixtures is crucial in the development technologies to help control diabetes.

A selection of other chemosensors that could be implemented for applications in the real world are discussed hereafter. Lippolis and co-workers have described a very simple example of a $\mathrm{Hg}^{2+}$ optode by incorporating receptor 15 , into a PVC membrane, (Fig. 12). This system is able to detect $\mathrm{Hg}^{2+}$ in real samples such as an amalgam alloy, hair and well water. ${ }^{78}$

The sensor is commercially available from Merck.

The recognition of various methamphetamines (MDMA, cocaine, amphetamine, and 3-fluoromethamphetamine) through a synergistic effect of weak interactions (H-bonds, $\mathrm{CH}-\pi)$ was achieved using tetraphosphonate cavitands. ${ }^{79}$ In particular, pyrene-tetraphosphonate cavitands embedded into using silica nanoparticles have been successfully demonstrated by Dalcanale, Prodi and co-workers to detect ecstasy in water. ${ }^{80}$ As shown in Fig. 13, the pyrenes in the distal position can form an excimer which is the transducer element of the chemosensor. In the presence of a bulky $N$-methylammonium guest the excimer formation is perturbed, and the monomer emission can be observed.

The same class of compounds, anchored on silicon surfaces, have also been used to recognize sarcosine (recently linked to the occurrence of aggressive prostate cancer forms) from its nonmethylated precursor glycine, in water and urine. ${ }^{81}$ The selective molecular recognition of sarcosine by a tetraphosphonate cavitand was further implemented to develop an electroluminescent approach. ${ }^{82}$ Generating luminescence via electrochemistry allows for very low background and high sensitivity, good temporal and spatial resolution, robustness, versatility, and low fabrication cost. ${ }^{83}$ In a typical electrochemiluminescence experiment in water, the energy to generate the emitting excited state comes from an electrochemical oxidation-reduction process between a dye, classically $\mathrm{Ru}(\mathrm{bpy})_{3}{ }^{2+}$, and a co-reactant (typically an amine that can partially deprotonate forming a reactant radical that can reduce the dye to $\mathrm{Ru}(\mathrm{bpy})_{3}{ }^{+}$). At the same time $\mathrm{Ru}(\mathrm{bpy})_{3}{ }^{2+}$ can be oxidized at the electrode surface and react with its reduced form generating the emitting excited state $\mathrm{Ru}(\mathrm{bpy})_{3}{ }^{2+}$. In this case, sarcosine acts as the co-reactant able to reduce the ruthenium complex. By functionalising the surface of magnetic beads with the cavitand, the authors were able to form a complex with sarcosine at acidic $\mathrm{pH}$; separate the complex from the matrix by capturing the magnetic beads with a magnetic field; release sarcosine by increasing the $\mathrm{pH}$; and measure its concentration via electrochemiluminescence. ${ }^{82}$

Anslyn has long been a pioneer within the field of chirality detection, it was almost 20 years ago that a simple, yet very elegant dynamic four-component reversible covalent assembly for secondary alcohol binding was proposed, Fig. $13 .{ }^{84}$ The reversible self-assembly of pyridine-2-carboxaldehyde, di-(2pyridylmethyl)amine, $\mathrm{Zn}(\mathrm{OTf})_{2}$ and a secondary alcohol lead to the generic complex 16, Fig. 14, which was easily characterized via ${ }^{1} \mathrm{H}$ NMR, and circular dichroism demonstrated the chiral discrimination of secondary alcohols. Such dynamic assemblies are studied towards the development of molecular machines and 
<smiles>COc1cc(CCNc2ccc3c4c(cccc24)C(=O)N(CC2=CC=C4C=CC=CC=CC=C2COP(=O)(O)CNC4=O)C3=O)ccc1N1CCOCCOCCOCCOCC1</smiles>

12

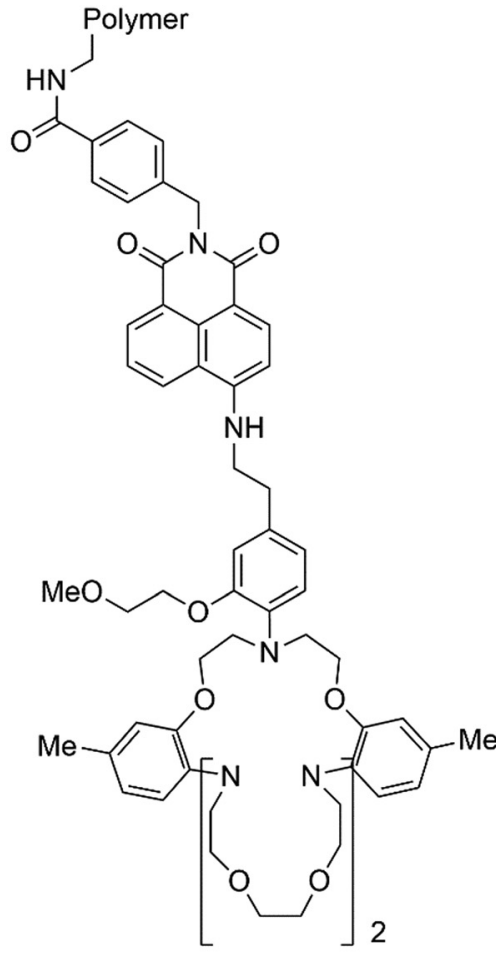

13<smiles>CCOc1cc(N(CCOCC(=O)[O-])CCOCC(=O)[O-])c(OCC)cc1CCNc1ccc2c3c(cccc13)C(=O)N(CC1=CC=C3C=CC=CC=CC=C1COP(=O)(O)CNC3=O)C2=O</smiles>

14

Fig. 11 Structure of sensors 12-14.

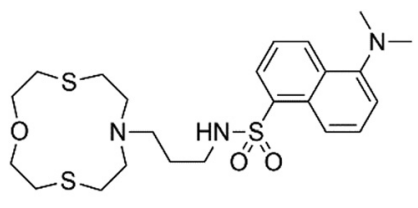

15

Fig. 12 Structure of chemosensor 15

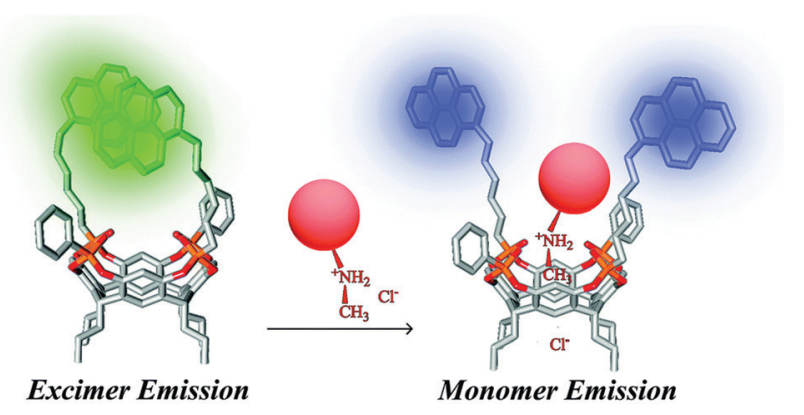

Fig. 13 Proposed sensing mode for ecstasy recognition. ${ }^{80}$ Reproduced from ref. 80 with permission from the Royal Society of Chemistry, copyright 2015.

complex architectures on an atomic scale, with applications in a variety of fields. ${ }^{85}$

Paolesse and co-workers have shown various examples of sensors based on supramolecular porphyrin aggregates. ${ }^{86}$
These researchers have recently demonstrated that grafting chiral porphyrin derivative $\mathbf{1 7}$ onto $\mathrm{ZnO}$ nanoparticles could yield a gas sensor, able to detect and recognize vapours of enantiomeric pairs, Fig. 15(a). ${ }^{87}$ By layering this material onto quartz microbalances the authors were able to evaluate the total amounts of adsorbed analytes and the relative magnitude of stereoselective interactions with respect to overall interactions when the films were exposed to vapours of $(R)$ - and $(S)$ limonene, $(R)$ - and $(S)$-butan-2-ol, and (-)- and (+)- $\alpha$-pinene enantiomers, displaying a remarkable selectivity for limonene enantiomers.

Parker and co-workers have extensively studied lanthanide complexes as emissive optical probes to detect key biochemical species such as citrate, lactate and urate. ${ }^{8-90}$ An assay to measure uric acid in biological fluids was developed by using the luminescent $\mathrm{Tb}^{3+}$ complex 18, Fig. 15(b). By evaluating the Stern-Volmer quenching constants, representing the concentration of analyte needed to reduce the lifetime or emission intensity to $50 \%$ of its original value, these authors demonstrated that urate quenching was 50 times more effective than ascorbate.

This result is particularly appealing as the classic clinical assay used for uric acid detection is an enzymatic assay that is subject to interference from ascorbate. ${ }^{91}$ Parker is the co-founder of FScan Ltd, a University-based company in Durham (UK), which is focused on the development of commercial applications from its luminescent lanthanide chemistry technology platform. In particular they have developed a prostate cancer test using citrate level analysis in semen or prostatic fluid 


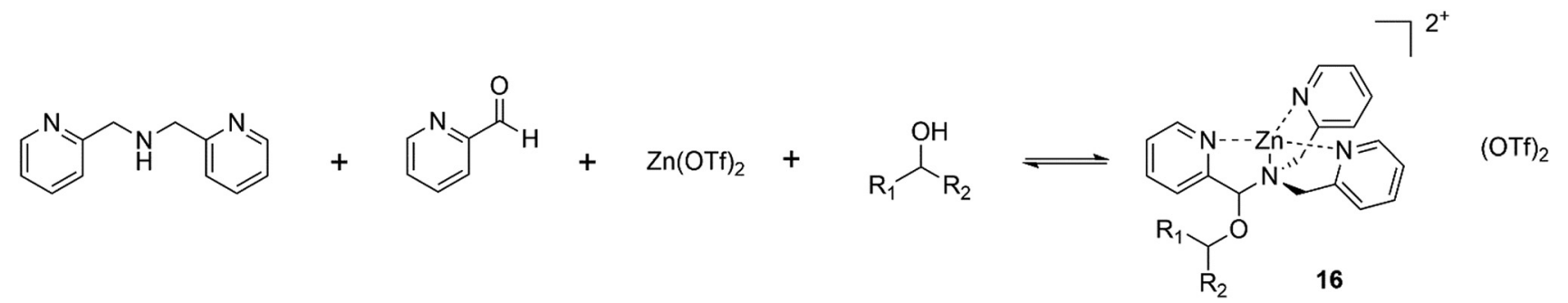

Fig. 14 Self-assembly of pyridine-2-carboxaldehyde, di-(2-pyridylmethyl)amine, $\mathrm{Zn}(\mathrm{OTf})_{2}$ and a secondary alcohol to give $\mathbf{8}$, capable of chiral discrimination through circular dichroism or ${ }^{1} \mathrm{H}$ NMR.
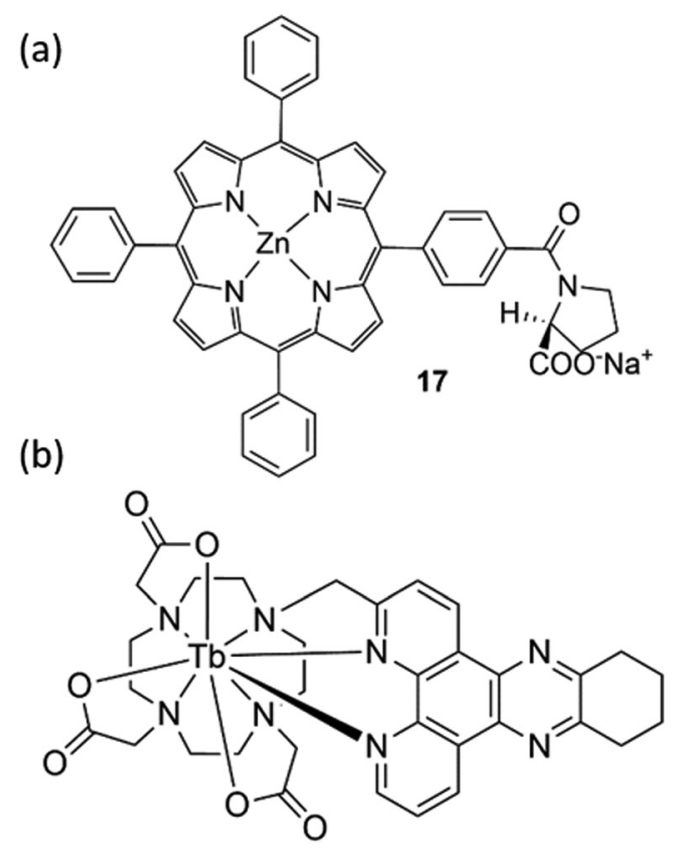

18

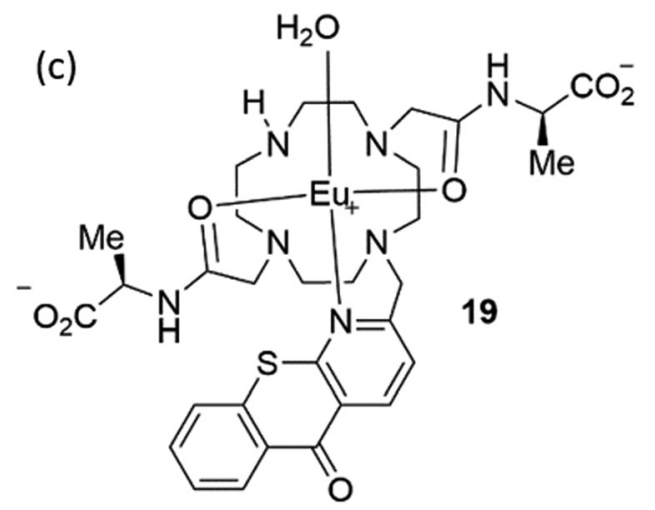

Fig. 15 The structure of chemosensors (a) 17, (b) 18 and (c) 19 .

samples. The sensor is based on a luminescent $\mathrm{Eu}^{3+}$ complex (19) able to selectively bind citrate, Fig. 15(c). ${ }^{92}$

In addition, a great contribution to the field of molecular imaging has been made by Smith and co-workers, ${ }^{93}$ who have produced an efficient imaging agent for the detection of mammary and prostate tumors. This was developed based on
zinc(II)-dipicolylamine (Zn-DPA) unit and a near infrared carbocyanine fluorophore (20), shown in Fig. $16 .{ }^{94}$ Due to the presence of $\mathrm{Zn}$-DPA, which is well known for its affinity for phosphorylated peptides, ${ }^{95}$ sensor 20 is able to target dead and dying cells with exposed anionic phosphatidylserine and can selectively accumulate in prostate and mammary tumour cells. Interestingly, the same sensor was successfully used to detect cell death in a brain cryolesion mouse model that replicates certain features of traumatic brain injury. ${ }^{96}$ Smith and co-workers have also developed squaraine rotaxanes as a novel family of deep-red fluorescent dyes with extremely high brightness and stability. ${ }^{97-100}$ These dyes exhibit high stability of the encapsulated squaraine which is protected from the attack of water thanks to the interlocked rotaxane structure.

Vapochromic materials are an interesting class of chemosensors with potential environmental applications. These materials are able to change colour/fluorescence when exposed to vapours of<smiles>COc1ccc2c(c1)C(C)(C)/C(=C/C=C1\CCCC(/C=C/C3[NH+](CCCC[S+](=O)[O-])c4ccc(OC)cc4C3(C)C)=C1Oc1ccc(C(=O)NCCCCOc3cc(CN(Cc4ccccn4)Cc4ccccn4)cc(CN(Cc4ccccn4)Cc4ccccn4)c3)cc1)[NH+]2CCCCS(=O)(=O)[O-]</smiles>

Fig. 16 The structure of chemosensor 20. 
volatile compounds. The first example of a vapochromic chemosensor was reported by Mann and co-workers in the late 1990s and is based on $\left[\mathrm{Pt}(\text { arylisocyanide })_{4}\right]\left[\mathrm{Pt}(\mathrm{CN})_{4}\right]$ (where aryl-isocyanide = $p$ - $\left.\mathrm{CNC}_{6} \mathrm{H}_{4} \mathrm{C}_{n} \mathrm{H}_{2 n+1} ; n=1,6,10,12,14\right)$ complexes which undergo a bathochromic shift in the NIR region upon exposure to volatile organic compounds (VOCs). ${ }^{101}$ Since this time two main classes of vapochromic materials have been developed. The first based on coordination complexes or organometallic compounds and the second on organic compounds, as recently reviewed by Huang and co-workers. ${ }^{102}$ Recent research from this group has led to the development of vapochromic materials, based on nonporous adaptive crystals (NACs) formed from pillar $[n]$ arenes. ${ }^{103}$

A transformation of the NACs structure occurs upon exposure to vapours of certain guest molecules, resulting in the generation of intrinsic or extrinsic porosity. With the guest molecules removed the NAC structure returns to a nonporous state. For example, NACs of pillar[4]-arene[1]quinone work particularly well in detecting vapours of aliphatic aldehydes of different chain lengths. ${ }^{104}$ Adsorption of these aldehydes leads to a colour change of this NAC. Crystal structure analysis reveals this colour change is due to alteration of the $\pi-\pi$ stacking interactions between the benzoquinone and the 1,4-diethoxybenzene units of the pillar[4]-arene[1]quinone scaffold.105

Additionally, the fluorescence emission properties of an anthracene appended pillar[5]-arene (21) NAC were also found to alter upon exposure to vapours of short chain alkyl ketones such as 2-butanone, 2-pentanone, and 2-hexanone (Fig. 17). ${ }^{106}$ Within this material, observed fluorescence is attributed to the formation of an excimer between two adjacent anthracene moieties. On adsorption of an appropriate short chain ketone the excimer is disrupted and the fluorescence of the monomeric anthracene only is observed. Further to the use of NACs as vapochromic receptors, their application in chemical purification is outlined later in this review.

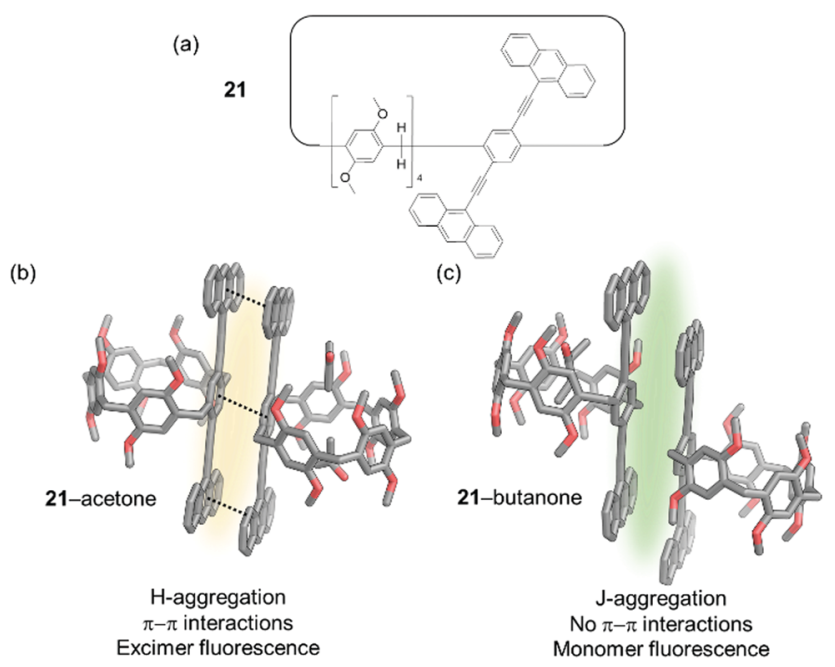

Fig. 17 (a) The structure of macrocycle 21; (b) fluorescence emission of $\mathrm{H}$-aggregated $\mathbf{2 1}$ caused by excimer formation; (c) fluoresce emission of J-aggregates of $\mathbf{2 1}$ caused by monomer emission. ${ }^{106}$

\section{Chemical warfare agent sensing and remediation}

Chemical warfare agents (CWAs) such as organophosphorus (OP) species and sulfur mustards (HD) are volatile and highly toxic molecules and potentially lethal, uncontrollable weapons when deployed. ${ }^{107}$ Due to the continued use of these agents in conflict situations and attacks on civilians, there is continued research into methods to remediate these compounds after release and to sense their presence. Such technology would also be of military value to mitigate the risks of producing and storing these species. As a result, significant effort has been put in over recent years to develop sensors able to recognize phosphorous-containing nerve agents. Gale and co-workers have described several examples of ureas/thioureas ${ }^{108-110}$ or polyureas able to recognize the chemical warfare agent soman (GD) and other organophosphorous species. The recognition event relates to the formation of $\mathrm{H}$-bond interactions between the organophosphonate guests and the urea/thiourea hosts. Some of the proposed systems were able to form organogels and in the presence of the organophosphorous species a disruption of the material could be observed as a sensory output. $^{111-115}$

The first example of fluorescent chemosensors for phosphonate recognition, able to give a turn-on fluorescent response in the presence of hydrolysis products of the nerve gas sarin, isopropyl methylphosphonate (IMP), and methylphosphonate (MP) was reported by Anzenbacher and co-workers. ${ }^{116}$ Eight fluorescent tripodal sensors with a 1,3,5-triethylbenzene core were dissolved in DMSO and found to give a finger printed response for IMP and MP over other common anions, as demonstrated by linear discrimination analysis (LDA). A chromogenic probe based on BODIPY (22) was developed in Martínez-Máñez group for the detection of DFP (a sarin and soman mimic) and DCNP (a tabun mimic). ${ }^{117}$ As shown in Fig. 18 this system has three reactive sites; i.e. (i) a nucleophilic phenol

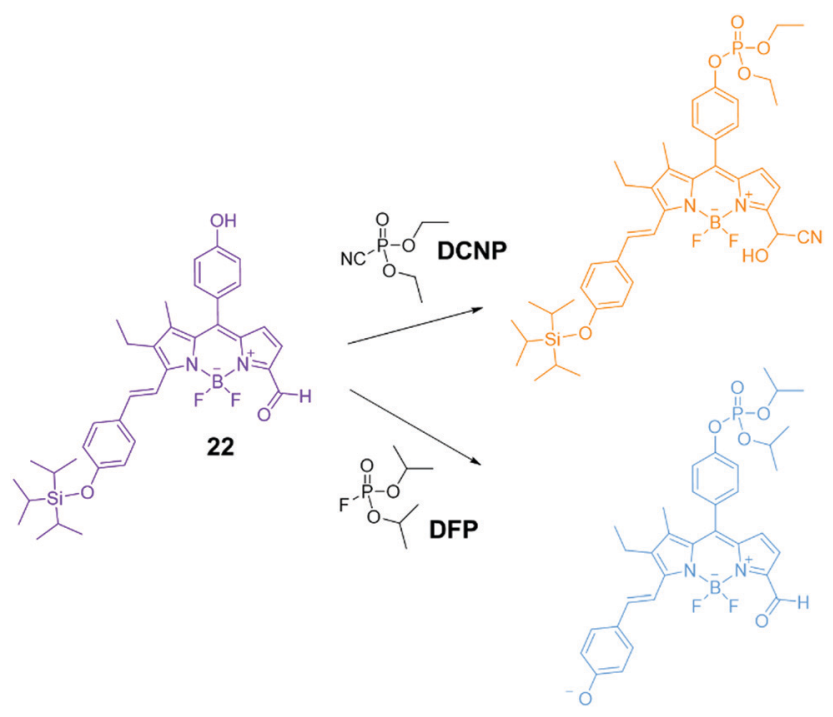

Fig. 18 Proposed mechanism of the chromogenic response of sensor 22 in the presence of DCNP and DFP. ${ }^{117}$ Reproduced from ref. 117 with permission from the Royal Society of Chemistry, copyright 2016. 
group able to undergo phosphorylation with nerve gases, (ii) a carbonyl group as a reactive site for cyanide; and (iii) a triisopropylsilyl (TIPS) protecting group that is known to react with fluoride. The colour change in response to fluoride or cyanide is indicative of the presence of DFP or DCNP respectively. Dramatic and differing colour changes were observed in MeCN upon addition of one equivalent of DFP and DCNP, showing the ability of this system to detect and differentiate these CWA mimics.

Although OP species eventually degrade via hydrolysis, this is a slow process at neutral $\mathrm{pH}$. To avoid the use of excess base or other reagents, ${ }^{107}$ catalysis underpinned by molecular recognition strategies has been investigated as a route to promote the hydrolysis of bound OPs to safe by-products. However, investigating strategies to remediate or sense live CWAs is extremely challenging due to the acute toxicity of these species. While significant progress has been made using simulants of lower toxicity and greater ease of handling, their behaviour invariably differs from live agents. ${ }^{107}$ Here we will discuss recent reports that show progress in the remediation of live CWAs which demonstrate the potential for application in the field.

The application of supramolecular chemistry towards this purpose has focussed on strategies to immobilise the agent and subsequently trigger its breakdown, with recent progress made in systems which can achieve both of these elements. While organogels formed from gelators that can act as destructive agents to trigger the decomposition of the CWA are known, it is also possible to immobilise reactive decontaminants within an organogel matrix to form a multicomponent material from simple precursors. ${ }^{114,118}$ In recent work funded by the Defence Science and Technology Laboratories (Dstl), Holder, Blight and co-workers examined the immobilisation of a catalytic metal organic framework (MOF) inside a polymer sponge network. ${ }^{119}$ This work combined the previously reported ability of styrenic poly high internal phase emulsions (pHIPEs) to swell and trap a range of OP and mustard series nerve agents ${ }^{120}$ with the known propensity of zirconium MOFs to function as heterogeneous catalysts for the hydrolysis of OPs. ${ }^{121}$ The authors prepared a composite material consisting of a styrene or vinyl based pHIPEs and zirconium MOF-808 at a loading of $25 \mathrm{wt} \%$ relative to the monomer weight. MOF-808 was chosen due to its activity in catalysing OP hydrolysis, and because the linker is commercially available making this MOF suitable for cost-effective scale-up. Phosphorus NMR studies using the CWA simulant dimethyl $p$-nitrophenylphosphate (DMNP) indicated that OP hydrolysis was significantly accelerated in the presence of the composite material in $0.45 \mathrm{M}$ NEM buffer and $\mathrm{THF} / \mathrm{H}_{2} \mathrm{O} / \mathrm{D}_{2} \mathrm{O}$ $(2: 1: 1)$, and performed better than experiments in which the catalytic MOF was added as a powder, due to the better dispersion of the catalyst. Minimal hydrolysis was observed in the absence of the MOF. Following on from this, hydrolysis studies using the live agent VX demonstrated that the composite materials could trigger hydrolysis in $\mathrm{THF} /$ water solution, with half-lives of 1 hour. Furthermore, neat VX could also be degraded in the absence of any solvent; with a total MOF-808 catalyst loading of $0.18 \%$ relative to VX, near full hydrolysis was observed after 2 weeks under ambient humidity. Over the same period without catalysis, the hydrolysis of VX would be expected to reach $50 \%$ completion only. The authors noted that potentially $4.5 \mathrm{~kg}$ of the composite would be able to absorb, immobilise and degrade the entire contents of a standard barrel (208 L) of VX.

\section{Supramolecular separations and hydrometallurgy}

Supramolecular and coordination chemistry have been fruitfully applied in the extractive metallurgy of metals such as copper, nickel, cobalt and zinc for a number of years. ${ }^{122}$ Solvent extraction using phenolic oxime ligands, extensively studied by Tasker, ${ }^{123}$ has accounted for up to $c a .25 \%$ of global copper production. $^{124}$ IBC Advanced Technologies, Inc. (IBC), ${ }^{125}$ cofounded by Izatt, Bradshaw and Christensen in 1988, have pioneered the use of so-called 'Molecular Recognition Technology' (MRT) - macrocycles such as BOB Calix (a calixarene-crown ether) - for the selective removal or exchange of metal ions. This type of technology has been used in applications such as the removal of caesium from nuclear waste at the Savannah River Site ${ }^{126}$ and its potential in green chemistry approaches to metal recovery from electronic waste has been recently highlighted. ${ }^{127}$

One area of recent progress has been in the application of supramolecular hosts for the isolation of precious metals such as gold. ${ }^{128}$ Key advances in this field have targeted lowering both the costs and the environmental footprint of precious metal mining projects, avoiding the use of highly toxic and environmentally damaging reagents such as cyanide. Another target is the capacity to recycle gold from Waste Electrical and Electronic Equipment (WEEE), such as mobile phones and computers, which represents an 'urban mine' for gold that could reduce the requirement for environmentally damaging mining processes. ${ }^{129,130}$ Approaches to this challenge have been recently reviewed by Love, ${ }^{129}$ who highlighted that a typical waste printed circuit board contains up to 60 different chemical elements, ${ }^{131}$ thus demonstrating the need for selectivity in precious metal extraction.

Notable progress in supramolecular approaches to gold extraction has been made based on the work of Stoddart et al., who first reported the capacity of $\alpha$-cyclodextrin to recognise and isolate gold in the form of alkali metal haloaurate salts (produced from gold bearing raw materials through etching followed by neutralisation) in $2013 .{ }^{132}$ The underlying principle of this work is the spontaneous precipitation of an extended $\left\{\left[\mathrm{K}\left(\mathrm{OH}_{2}\right)_{6}\right]\left[\mathrm{AuBr}_{4}\right] \subset(\alpha \text {-cyclodextrin })_{2}\right\}_{n}$ chain superstructure from water. Metallic gold can then be isolated from the $\alpha \cdot \mathrm{Br}$ precipitate by reduction with sodium metabisulfite $\left(\mathrm{Na}_{2} \mathrm{~S}_{2} \mathrm{O}_{5}\right)$, while the $\alpha$-cyclodextrin can be recovered for re-use by recrystallisation. This extraction strategy inspired the establishment of Cycladex in $2014,{ }^{133}$ a company whose mission is to reduce operating costs and toxic waste byproducts in commercial precious metal extraction. As a result of these efforts a patented method by which precious metals can be 
recovered has been developed, ${ }^{134}$ and the company has reportedly demonstrated this in a pilot plant at the ton level. ${ }^{135}$

The success of Cycladex has also inspired studies into gold precipitation using other macrocyclic hosts. Tao et al. reported that cucurbit[8]uril ( $\mathrm{CB}[8])$ macrocycles can imprison $\left[\mathrm{AuCl}_{4}\right]^{-}$ anions through co-precipitation in honeycomb-like frameworks. ${ }^{136}$ Cucurbiturils $(\mathrm{CB}[n] \mathrm{s})$ are known to form supramolecular frameworks through precipitation/crystallisation, which arise due to interactions between the positively charged outer surface of the $\mathrm{CB}[n]$ with either the negatively charged opening portals of adjacent $\mathrm{CB}[n] \mathrm{s}$ or with structure directing agents, such as anions. In this case, Tao et al. observed that $\left[\mathrm{AuCl}_{4}\right]^{-}$anions were trapped between macrocycles via outer surface interactions yielding an extended $\mathrm{CB}[8]$ framework (Fig. 19). The direct combination of $\mathrm{CB}[8]$ and $\mathrm{HAuCl}_{4}$ in aqueous $\mathrm{HCl}$ or $\mathrm{HNO}_{3}$ yielded framework $\mathbf{F 1}$, in which six $\left[\mathrm{AuCl}_{4}\right]^{-}$anions were contained in hexagonal cavities defined by six $\mathrm{CB}[8]$ macrocycles. This process was largely unaffected by the presence of other metal chlorides including $\mathrm{ZnCl}_{2}, \mathrm{CdCl}_{2}, \mathrm{NiCl}_{2}, \mathrm{CoCl}_{2}$, $\mathrm{MnCl}_{2}, \mathrm{FeCl}_{3}$ and $\mathrm{CuCl}_{2}$ and $\mathrm{H}_{2} \mathrm{PtCl}_{6}$ if the precipitation was performed from hot solutions; however, some co-crystallisation of $\left[\mathrm{PtCl}_{6}\right]^{2-}$ occurred if the samples were left overnight. Frameworks $\mathbf{F} 2$ and $\mathbf{F 3}$, formed in the absence of $\left[\mathrm{AuCl}_{4}\right]^{-}$anions, could take up $\left[\mathrm{AuCl}_{4}\right]^{-}$to yield framework F1. Meanwhile, gold could be isolated from framework F1 through reduction with hydrazine, producing a mixture of framework $\mathbf{F} 2$ and metallic gold. Thus, a route was developed by which gold can be isolated

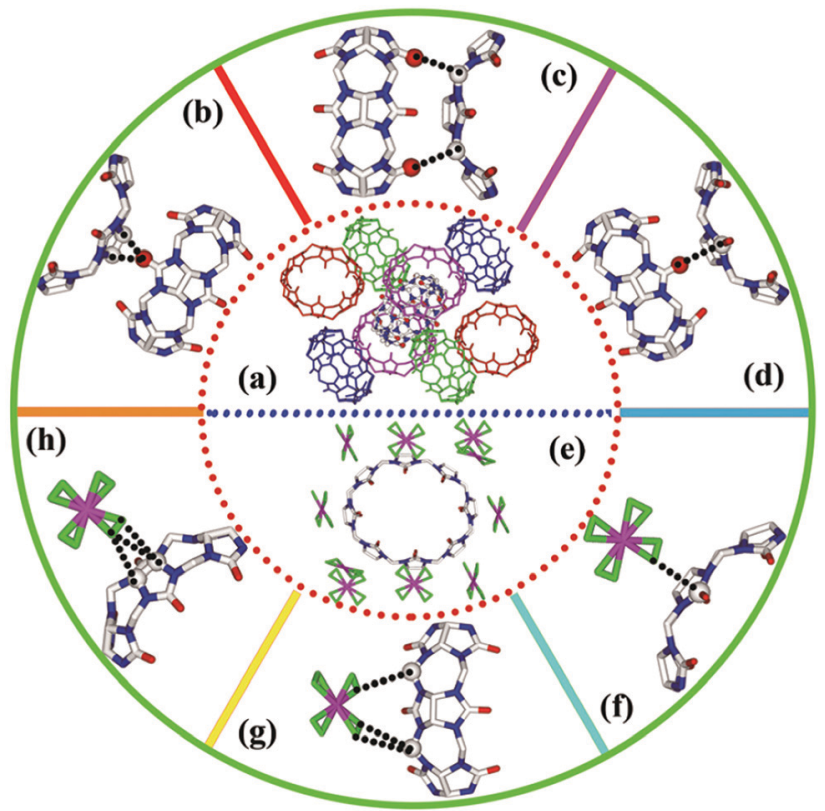

Fig. 19 (a) Crystal structures showing the relationship of the central $\mathrm{CB}[8]$ molecule with eight neighbouring macrocycles in F1 and F2, reported by Tao et al.; $(b-d)$ representative outer surface interactions between the central $\mathrm{CB}[8]$ molecule with neighbouring macrocycles; (e) the arrangement of ten $\left[\mathrm{AuCl}_{4}\right]^{-}$anions around the central $\mathrm{CB}[8]$ macrocycle; $(\mathrm{f}-\mathrm{h})$ representative outer surface interactions between the central $C B[8]$ macrocycle and ten surrounding $\left[\mathrm{AuCl}_{4}\right]^{-}$anions. ${ }^{136}$ Reproduced from ref. 136 with permission from the Royal Society of Chemistry, copyright 2019. from aqueous solutions of $\left[\mathrm{AuCl}_{4}\right]^{-}$with the regeneration of a host framework which could be re-used.

Following on from this work, the groups of $\mathrm{Tao}^{137}$ and Stoddart $^{138}$ have independently examined the ability of smaller cucurbit $[n]$ uril $(\mathrm{CB}[n=5-7])$ macrocycles to precipitate $\left[\mathrm{AuCl}_{4}\right]^{-}$ and $\left[\mathrm{AuBr}_{4}\right]^{-}$anions from acidic aqueous solution. The smaller $\mathrm{CB}[n]$ macrocycles are easier to synthesise and isolate than $\mathrm{CB}[8]$, hence a recovery process using these homologues is attractive on economic grounds. Tao et al. discovered that $\mathrm{CB}[n=5-7] \mathrm{s}$ can each bind to and co-precipitate $\left[\mathrm{AuCl}_{4}\right]^{-}$anions, with a range of coordination modes and stoichiometries observed via single crystal X-ray diffraction. A common feature was the interaction of the $\left[\mathrm{AuCl}_{4}\right]^{-}$anions with the exterior surface of the $\mathrm{CB}[n]$, including ion-dipole interactions between $\left[\mathrm{AuCl}_{4}\right]^{-}$anions and the portal carbonyl groups of the macrocycle and $[\mathrm{Au}-\mathrm{Cl} \cdots \mathrm{H}-\mathrm{C}]$ hydrogen-bonding interactions between $\left[\mathrm{AuCl}_{4}\right]^{-}$anions and methylene or methine hydrogen atoms (Fig. 20), as also observed in the distinct structures obtained by Stoddart et al. from $\mathrm{CB}[6]$ and both $\left[\mathrm{AuCl}_{4}\right]^{-}$and $\left[\mathrm{AuBr}_{4}\right]^{-}$ anions.

Interestingly, $\mathrm{CB}[7]$ was observed to form $\left[\mathrm{Au}\left(\mathrm{OH}_{2}\right)_{4}\right]^{3+} \subset$ $\mathrm{CB}$ [7] inclusion complexes, leading Tao et al. to suggest that $\mathrm{CB}$ [7] has the most suitable cavity dimensions to encapsulate this hydrated cation. Additionally, Tao observed that $\mathrm{CB}[6]$ exhibited better performance in gold extraction experiments than the other $\mathrm{CB}[n]$ homologues, while an optimised protocol from Stoddart ${ }^{138}$ achieved an impressive gold recovery efficiency of $99.2 \%$ based on the co-precipitation of $\mathrm{CB}[6]$ and $\mathrm{HAuCl}_{4}$. This extraction efficiency is greater than the $78 \%$ achieved with $\alpha$-cyclodextrin. ${ }^{139}$ The extraction was selective for gold over $\mathrm{Cu}, \mathrm{Zn}$ and $\mathrm{Ag}$ (Stoddart) and $\mathrm{Cu}, \mathrm{Cd}, \mathrm{Ni}$, and $\mathrm{Zn}$ (Tao). Both groups observed that reduction with hydrazine hydrate could yield gold metal and allow recovery of the macrocycle for re-use.

Love et al. have focussed on strategies to isolate gold from WEEE waste through solvent extraction. They reported a series of simple amides 23-25 (Fig. 21(a)) able to extract $\left[\mathrm{AuCl}_{4}\right]^{-}$from acidic single-metal and simulated WEEE solutions into toluene and other hydrophobic solvents. ${ }^{140,141}$ Insight from ESI-MS, density functional theory and molecular dynamics studies

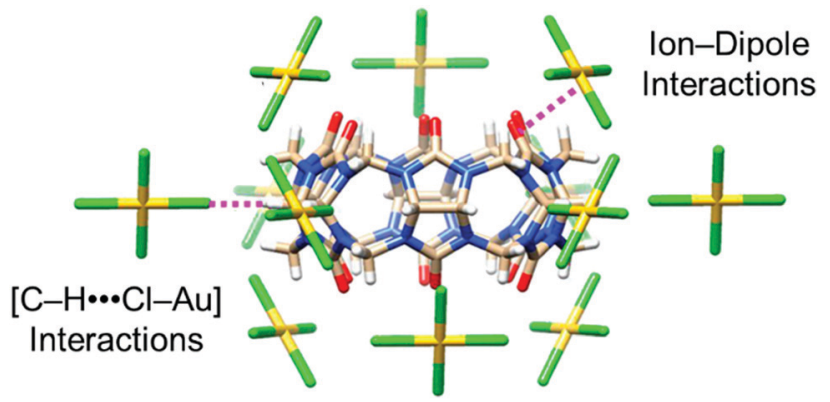

Fig. 20 Stick representation of the X-ray crystal structure of (CB[6]. $\left[\mathrm{AuCl}_{4}\right]^{-}$), reported by Tao and co-workers. ${ }^{137}$ The CB[6] macrocycle is surrounded by $12\left[\mathrm{AuCl}_{4}\right]^{-}$anions, which form interactions with the outer surface of the macrocycle. Reproduced from ref. 137 with permission from the American Chemical Society, copyright 2020. 
(a)
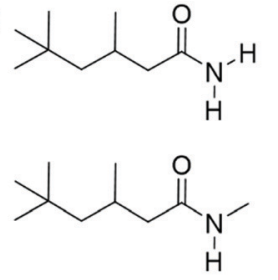

24

(b)

23

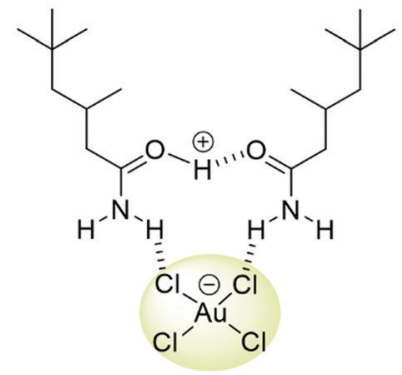

Fig. 21 (a) The structure of ligands $23-25$, reported by Love; (b) extraction of $\left[\mathrm{AuCl}_{4}\right]^{-}$is thought to occur via the formation of clusters of one protonated and one neutral ligand.

involving 23 indicated that phase transfer occurred through the assembly of clusters of $\left[\mathrm{AuCl}_{4}\right]^{-}$with one protonated and one neutral amide, yielding overall charge neutral structures stabilised by a combination of hydrogen bonding and columbic attraction (Fig. 21(b)). ${ }^{140}$ The overall charge neutrality of the clusters means that ion pairing is not required for transport into the organic phase to occur. Primary amide 23 demonstrated remarkable selectivity for extracting gold from mixedmetal systems representative of mixtures obtained by acidic leaching of printed circuit boards, such as those found in mobile phones. Once the organic solvent phase containing these clusters had been isolated, the addition of a clean, aqueous solution resulted in the back transfer of the $\left[\mathrm{AuCl}_{4}\right]^{-}$ into the new aqueous phase. This allowed the gold to be easily isolated and the ligand to be re-used for further extractions. Ligands $\mathbf{2 4}$ and 25 were found to extract $\left[\mathrm{AuCl}_{4}\right]^{-}$more efficiently than 23 from single metal solutions; however, their efficiency in extracting gold from mixed metal solutions was greatly reduced. The authors found that the presence of other metals such as $\mathrm{Fe}$ (III) and $\mathrm{Sn}$ (Iv) caused the formation of a goldrich third phase in extractions using 24 and 25 . The presence of $\mathrm{Fe}(\mathrm{III})$ and $\mathrm{Sn}(\mathrm{Iv})$ in the third phase in addition to $\left[\mathrm{AuCl}_{4}\right]^{-}$ complicated the clean isolation of gold species. This finding demonstrates the complications that can arise when increasing the complexity of model experiments to better represent realworld applications.

\section{Environmental remediation}

Oil spills are hugely damaging environmental disasters that have a severe, adverse effect on freshwater and marine ecosystems. ${ }^{142}$ Effective clean-up strategies can help to mitigate the damage caused by oil spills by dispersing or removing the oil from the aqueous environment. The use of organogelators in this application has been reviewed by Sureshan and Vibhute. ${ }^{143}$ Another established strategy for the remediation of light oil spills is the addition of elasticity agents, such as Elastol, ${ }^{144}$ to the oil. Elastol is a powdered formulation of a long-chain hydrophobic polymer which dissolves in the oil and modifies its mechanical properties through gelatinisation/solidification. The effect is to limit the dispersion of the oil and to increase the ease of physically recovering it from the surface of the water.
Targeting a similar remediation strategy, there is interest in developing supramolecular phase-selective organogelators (PSOGs) that can form organogels from biphasic oil/water mixtures and thus trap the oil. ${ }^{145}$ In a recent review, Okesola and Smith highlighted that supramolecular gelators with a plausible chance of application in this context must be based on low cost, non-toxic components and must gel rapidly in high salt conditions without the need for a carrier solvent, heating or agitation. ${ }^{146}$ The gels formed must be stable at low temperatures and to shear forces to aid with physical recovery. The possibility of recovering the oil via distillation is also economically attractive and could facilitate re-use of the gelator.

While a number of patents exist describing the application of supramolecular gelators such as dibenzylidene-D-sorbitol ${ }^{147}$ and 12-hydroxystearic acid ${ }^{148}$ in this context, developing PSOG systems that meet all of the above requirements remains an ongoing challenge. In recent work, Zhang, Wang, Song and co-workers reported gelators 26-28 (Fig. 22(a)) via a 2-step synthesis. ${ }^{149}$ While all three gelators formed stable gels in aromatic and hydrocarbon solvents via the heating-cooling method, and $\mathbf{2 6}$ and $\mathbf{2 8}$ could gel fuel oils such as kerosene and diesel with low critical gelation concentrations $(<0.1 \% \mathrm{w} / \mathrm{v})$, only gelator $\mathbf{2 6}$ could form room temperature, biphasic gels with fuel oils when applied as a powder (i.e. in the absence of a carrier solvent). A combination of FT-IR and ${ }^{1} \mathrm{H}$ NMR analysis indicated the self-assembly of 26-28 was driven by the synergistic formation of hydrogen bonding (amide and hydroxyl groups), $\pi-\pi$ stacking (aromatic units) and van der Waals forces (alkyl chains) as shown in Fig. 22(b). SEM, PXRD and FT-IR of xerogels and pristine powders indicated that unsaturation (26) or branching (27) in the chains of the gelators lead to looser packing in the solid state, yielding porous structures with lipophilic surfaces. The authors concluded that these structures were more accessible to oil solvents and that the van der Waals interactions between chains were weaker when the packing was looser and more easily disrupted by oil. Hence, only gelator $\mathbf{2 6}$ was able to dissolve to form a gel without a carrier solvent or heating.

Powdered gelator 26 was also found to gel a range of fuel oils including gasoline, diesel and seven types of crude oil in biphasic seawater mixtures without the need for a carrier solvent, heating or agitation. The gels formed at biphasic critical gelation concentrations between $2-7 \% \mathrm{w} / \mathrm{v}$, and were stable to acidic and basic media. Light oils could be gelled within 1 minute $(5 \% \mathrm{w} / \mathrm{v})$, although heavy crude oils required a longer gelation time (up to 7 minutes at $10 \% \mathrm{w} / \mathrm{v}$ ). Lighter oils could still be gelled at the lower temperature of $5{ }^{\circ} \mathrm{C}$, while heavier oils solidified. Rheometry measurements indicated good mechanical properties and strength which could mean that the gels are suitable for simple salvage in a remediation process. This gelator was also found to be non-toxic in zebrafish, and the crude oil recovery could be scaled up to recover $35 \mathrm{~mL}$ of crude oil in an attempt to better simulate a large scale, real-life recovery.

Another environmental problem that supramolecular chemistry has been applied to is the removal of organic micropollutants from water. These pollutants, such as pharmaceuticals and 
(a)
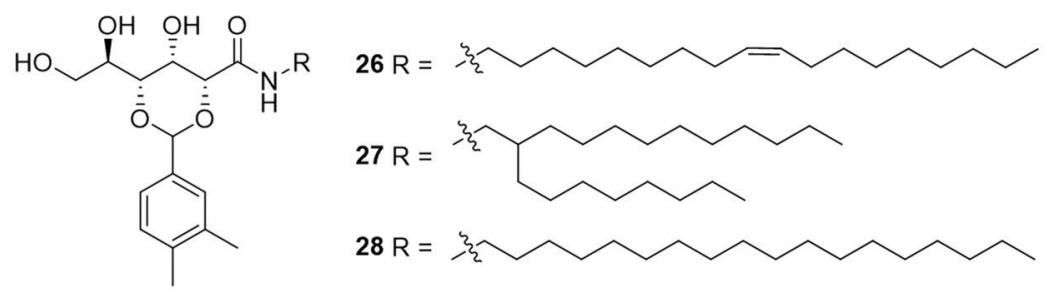

(b)

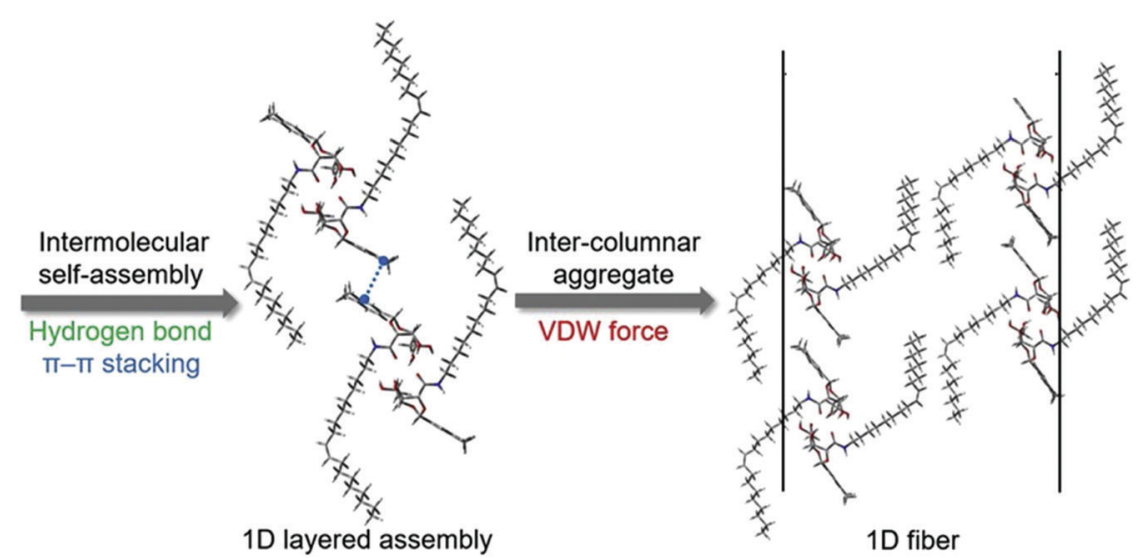

Fig. 22 (a) The structure of gelators 26-28; (b) Gelation of hydrophobic solvents occurs via the formation of intermolecular hydrogen bonds, $\pi-\pi$ stacking and van der Waals interactions between lipophilic chains. ${ }^{149}$ Adapted from ref. 149 with permission from Elsevier, copyright 2020.

organic dyes, have detrimental effects both to the health of ecosystems, and to human health. ${ }^{150}$ In response to this, Alsbaiee and co-workers have developed mesoporous polymers by crosslinking $\beta$-CD with tetrafluoroterephthalonitrile, yielding a material capable of forming host-guest complexes with a range of common organic pollutants including plastic components, pharmaceuticals, pesticides and aromatic carcinogens. Not only does this material offer adsorption rates of 15-200 times greater than leading alternatives, it can also be regenerated through mild washing processes with no loss in performance. ${ }^{151}$ Such technology would be well suited to continuous flow water treatment.

\section{Anion extraction from nuclear waste}

In 2013 a team of scientists lead by Bruce Moyer at Oak Ridge National Labs in the U.S., highlighted the potential for supramolecular anion recognition to be applied in the separation of sulfate from nuclear waste. ${ }^{152}$ The presence of sulfate causes numerous problems in the handling and long-term storage of nuclear waste, particularly in converting the waste into a form that is readily stored. However, the authors noted that that no technology to meet this need had yet been identified and concluded that there was great potential for molecularrecognition approaches to provide a solution to this problem. They noted that successful new technologies must be "competitive against a field of alternatives and therefore must fulfil a given industrial need with the least cost".

Despite the relative ease of engineering anion receptors that bind strongly to sulfate (particularly in organic solvents), its high hydration energy means that extracting sulfate from aqueous solution is challenging. Another key consideration for nuclear waste treatment is the ability to recognise and extract sulfate anions in the presence of high concentrations of nitrate anions, which are less hydrophilic and thereby an easier target to extract into a hydrophobic environment.

In 2018, Williams and Moyer et al. reported the simple di(imino)guanidinium receptor 29 -Cl shown in Fig. 23(a). ${ }^{18}$ The synthesis of this receptor was relatively straightforward (68.6\% over 3 steps). In liquid-liquid anion extraction experiments using 1,2-DCE as a receiving phase, 29 was found to efficiently extract sulfate from an aqueous phase and outperformed the commercial anion extractant Aliquat 336 (A336) in both extraction efficiency and selectivity. Receptor 29 displayed a remarkable selectivity for sulfate over chloride, even when chloride was present in $100 \times$ excess. When the extraction was performed with the solvent Isopar L (a commonly used solvent in industrial extractions), the selectivity factor (SF) for sulfate over chloride was as high as 4300 ; for context, the authors noted that SF values $>1$ are rare in the literature.

Further studies designed to better understand the cause of this selectivity were conducted. The isopar L solutions of 29-Cl were found to contain a high water content which increased linearly with the receptor concentration. Here small angle X-ray scattering data implied the formation of nanoscale colloidal structures thought to be reverse micelles in the organic phase.

Based on previous studies which suggested that iminoguanidiniums can interact with partially hydrated sulfate anions, ${ }^{153-155}$ the authors speculated that sulfate-water clusters could be extracted by 29-Cl. They reasoned that the sulfate anion cannot achieve coordinative saturation (12 hydrogen bonds) from 29-Cl receptors alone on steric grounds, and hence concluded that the sulfate must also be coordinated by 


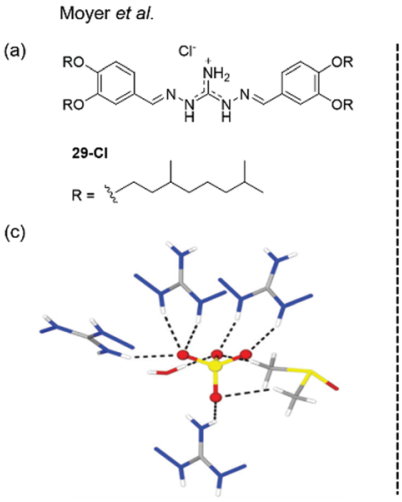

(b)

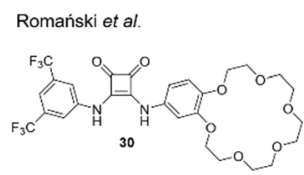

(d)

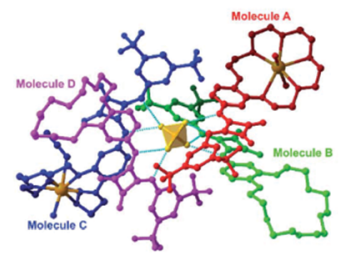

Fig. 23 (a) The structure of receptor 29, reported by Moyer and (c) X-ray crystal structure of the complex of a simple analogue of DIG with a sulfate anions, showing the dual-coordination by four receptors, one water molecule and one DMSO molecule. Adapted from ref. 17 with permission from The Royal Society of Chemistry; (b) the structure of ion pair receptor 30, reported by Romański et al. and (d) X-ray crystal structure of the complex of 30 with $\mathrm{Na}_{2} \mathrm{SO}_{4}$, showing the coordination of the sulfate anion by 4 receptors, forming a charge neutral complex via the inclusion of $2 x$ $\mathrm{Na}^{+}$ions in the benzocrown cavities. ${ }^{17,18}$ Adapted from ref. 18 with permission from the Royal Society of Chemistry, copyright 2018.

associated water molecules. Correspondingly, the X-ray crystal structure of a simpler analogue of $\mathbf{2 9}$ complexed with sulfate revealed that the anion was coordinated by four receptors and, one water molecule and one DMSO molecule (Fig. 23(c)). The ability of 29-Cl to extract sulfate without total de-solvation could explain the remarkable selectivity observed.

Recent work from Romański $e t$ al. reported the squaramidebased ion pair receptor 30 (Fig. 23(b)), able to extract $\mathrm{K}_{2} \mathrm{SO}_{4}$ from water into organic solvents. While many sulfate extraction systems have been based on charged anion receptors that produce charge-neutral, organic-soluble complexes with sulfate, this can require the use of bulky counterions. In this case the need for bulky counterions is avoided, since the neutral receptor can cooperatively bind to both anions and cations to achieve charge balance. Receptor $\mathbf{3 0}$ was found to interact with a range of monovalent anions forming $1: 1$ complexes, and the addition of one equivalent of $\mathrm{Na}^{+}$or $\mathrm{K}^{+}$lead to an enhancement in anion binding strength in all cases, with the greatest effect observed for $\mathrm{K}^{+}$due to preferential binding to the benzo-18-crown-6 unit. However, titrations with divalent $\mathrm{SO}_{4}{ }^{2-}$ revealed that more complex binding stoichiometries were forming. In particular, titrations with $\mathrm{TBA}_{2} \mathrm{SO}_{4}$ carried out in the presence of $\mathrm{K}^{+}$ produced a two-step binding isotherm that could not be fitted to a simple binding model. Careful analysis of the ${ }^{1} \mathrm{H}$ NMR titration data obtained in $\mathrm{CD}_{3} \mathrm{CN}$ solution indicated that a $4: 1$ (receptor:anion) complex forms under these conditions, and DOSY-NMR and DLS confirmed the formation of large supramolecular assemblies with hydrodynamic diameter $d_{\mathrm{H}}=28 \mathrm{~nm}$. The X-ray crystal structure of $\mathbf{3 0}$ with $\mathrm{Na}_{2} \mathrm{SO}_{4}$ is shown in Fig. 23(d), and demonstrates the formation of a 4:1 (receptor: anion) complex, in which the sulfate anion is encapsulated by four ligands (Fig. 23(d)). The overall complex remains charge neutral as two $\mathrm{Na}^{+}$cations are bound within the benzocrown cavities.

This difference in binding behaviour towards monovalent and divalent anions prompted the authors to investigate the ability of $\mathbf{3 0}$ to differentiate these species under extraction conditions. Atomic emission spectroscopy and ion chromatography were used to quantify the extraction efficiency of $\mathbf{3 0}$ towards $\mathrm{K}_{2} \mathrm{SO}_{4}$ from water to chloroform in the presence of different competing salts. An aqueous mixture of $\mathrm{KNO}_{3}$ and $\mathrm{K}_{2} \mathrm{SO}_{4}$ was extracted with a solution of $\mathbf{3 0}$ in chloroform; the concentration of sulfates in the aqueous phase was reduced by up to $74 \%$, whilst a drop of just $7.2 \%$ was observed for nitrate. The authors proposed that the greater organic-solubility of the $4: 1$ (receptor:anion) complexes formed with divalent anions compared to the $1: 1$ complexes formed with monovalent anions underpinned the extraction selectivity.

Recently, Jolliffe and co-workers have developed the lipophilic, macrocyclic squaramide receptor 31 shown in Fig. 24(a), which is capable of extracting sulfate from water into a hydrophobic solvent phase, and also of transporting sulfate across a bulk chloroform membrane in U-tube experiments. ${ }^{156}$ The authors suggest that the advantage of using a transport rather than extraction process for sulfate removal is that the extractant - in this case the organic macrocycle - can be

(a)

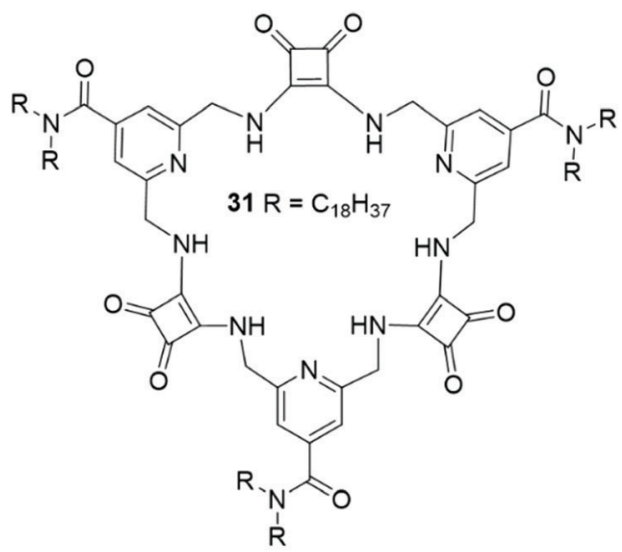

(b)

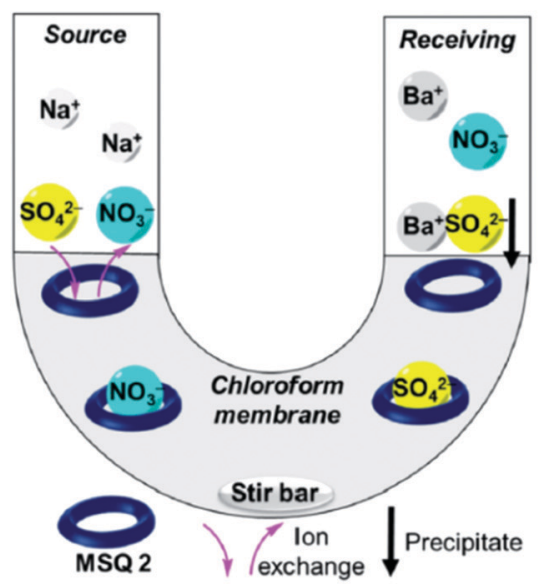

Fig. 24 (a) The structures of macrocyclic squaramide receptor 31; (b) the transport of sulfate across a bulk hydrophobic solvent phase. ${ }^{156}$ Reproduced from ref. 156 with permission from the Royal Society of Chemistry, copyright 2020. 
recovered for re-use. Macrocycle $\mathbf{3 1}$ was found to bind tetrabutylammonium sulfate strongly in chloroform- $d$ saturated with water $\left(K_{\mathrm{a}}>10^{4} \mathrm{M}^{-1}\right.$ determined by ${ }^{1} \mathrm{H}$ NMR titration) and extract $\mathrm{TBA}_{2} \mathrm{SO}_{4}$ from water into a chloroform- $d$ solution. Despite also forming strong complexes with nitrate anions $\left(K_{\mathrm{a}}>10^{4} \mathrm{M}^{-1}\right.$ in chloroform- $\left.d\right), 31$ could selectively extract sulfate from water to chloroform- $d$ in the presence of $\mathrm{TBANO}_{3}$. The identity of the extracted macrocycle-anion complex was determined based on distinct ${ }^{1} \mathrm{H}$ NMR signatures. However, the lipophilic tetrabutylammonium counterion was required for successful extraction, and no anion extraction was observed when only sodium salts were used. Washing a chloroform- $d$ solution of $31 \cdot \mathrm{SO}_{4}{ }^{2-}$ with aqueous $\mathrm{Ba}\left(\mathrm{NO}_{3}\right)_{2}$ lead to the precipitation of $\mathrm{BaSO}_{4}$ and generation of $\mathbf{3 1} \cdot \mathrm{NO}_{3}{ }^{-}$via anion metathesis. Based on this regeneration of the sulfate-free species, the authors designed a U-tube experiment to investigate sulfate transport across a bulk chloroform membrane (Fig. 24(b)). The sulfate concentrations of the aqueous phases were monitored over time using a modified $\mathrm{BaSO}_{4}$ gravimetric analysis coupled with ICP-MS. In the absence of an ion source in the organic phase, no transport was observed; however, when five equivalents of $\mathrm{TBANO}_{3}$ was dissolved in the organic phase, sulfate transport was enabled. A 2-fold increase in sulfate transport was obtained by adding $\mathrm{BaCl}_{2}$ to the receiving phase, which resulted in $\mathrm{BaSO}_{4}$ precipitation, removing sulfate from solution and driving the transport of further equivalents of the anion.

\section{Nonporous adaptive crystals in separations}

The separation and refinement of chemical species is an essential industrial process, with a large environmental and economic impact. Indeed, distillation currently accounts for between $10-15 \%$ of global energy consumption. ${ }^{157}$ In 2016 Sholl and Lively outlined 'seven chemical separations to change the world', offering adsorption and separation as a pathway to reducing the environmental impact. ${ }^{158}$ To be effective separation agents, adsorptive materials require high surface areas. Many such materials have been reported, including but not limited to, MOFs, ${ }^{159}$ covalent organic frameworks (COFs) ${ }^{160}$ and zeolites. ${ }^{161-163}$ Whilst these classes of materials represent steps forward within this field, large macromolecular structures lead to poor solubility, and the presence of reversible bonds often limit stability. These factors preclude the use of these materials in solution-based separation processes. Arguably the step-change within this area can be attributed to work by Huang and co-workers who have pioneered the development of NACs, utilizing supramolecular assembly to overcome these limitations. ${ }^{103}$ As previously discussed, NACs are nonporous in their initial crystalline state however, upon the introduction of guest species a reversible crystal structure transformation occurs, generating porosity in situ. Within the scope of this review we seek to bring to the reader's attention NAC separation systems with commercially relevant applications however, for a more inclusive review of this area we refer the reader to a mini review published by Yang, another of this fields forefathers. ${ }^{164}$
One of the first examples we wish to highlight from this area is that of Cooper, Huang and co-workers, who have demonstrated the ability of NACs constructed of pillar[5]arene 32 (EtP5) and pillar[6]arene 33 (EtP6), Fig. 25, to separate styrene and ethylbenzene, ${ }^{165}$ one of Sholl and Lively's seven targeted chemical separations. ${ }^{158}$ Styrene is used in the production of a variety of polymeric materials (e.g. synthetic rubbers, plastics and resins), and is produced through the dehydrogenation of ethylbenzene. Due to inefficiencies in this process, steam produced during the synthetic procedure often contains unreacted ethylbenzene, which must then be removed. Owing to the similar boiling points of styrene and ethylbenzene (146 and $136{ }^{\circ} \mathrm{C}$ respectively), ${ }^{166}$ conventional distillation is not practical, and as a result separating these two compounds requires complex and energy intensive processes. ${ }^{167}$ The authors instead utilize the EtP5 and EtP6 NACs, taking advantage of the small differences in the geometry of styrene and ethylbenzene (Fig. 26(a-c)), the presence of which initiates crystallization processes resulting in the formation of porous materials with differing stabilities. The crystalline material containing styrene is far more stable than that of ethylbenzene, meaning that the solid crystalline material containing the styrene prevails, and can easily be separated. Starting from a 50:50 mixture of ethylbenzene and styrene, this process has been shown to produce styrene with $>99 \%$ purity. Further to this, as the crystallization of EtP6 is directed by the presence of styrene, it is not necessary to start with crystalline EtP6, and as such it can be recycled through heating with no loss of styrene capturing ability, Fig. 26.

para-Xylene is another commercially important compound used in the production of a variety of polymers such as polyethylene terephthalate (PET) and polyester. ${ }^{158}$ However, the synthesis of this compound results in a mixture of ortho-, meta- and para-xylene, which again are difficult to separate using conventional distillation procedures. Here again the NAC EtP6 material was found to be effective in the separation of para-xylene from a mixture with its other isomers, achieving a purity of $90 \%$ and providing a less energy intensive route towards another industrially relevant starting material. ${ }^{168}$ In the interest of developing separation methodologies with even lower energy demands, Khasab and co-workers have further developed this work. These authors utilized a water soluble pillar[5] arene derivate to perform separations of xylene isomers

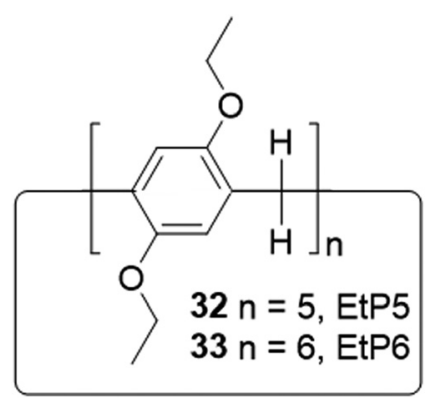

Fig. 25 The general structure of pillar[n]arenes. 
(a)
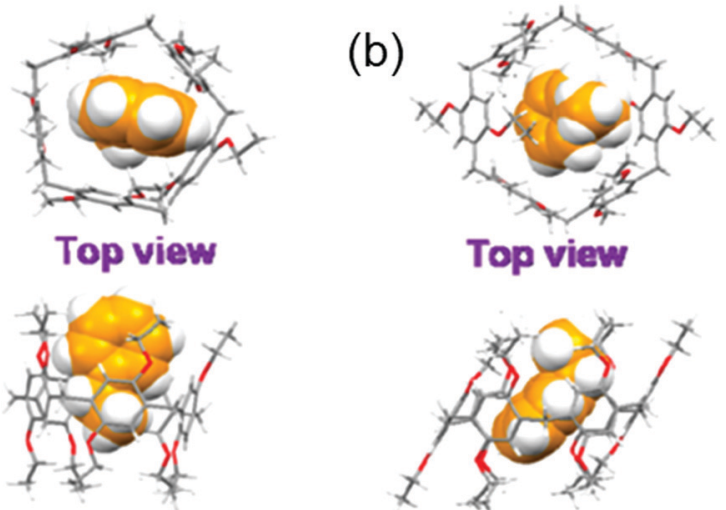

Side view

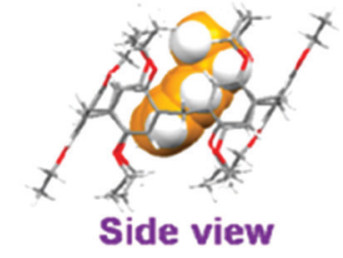

Side view

(c)

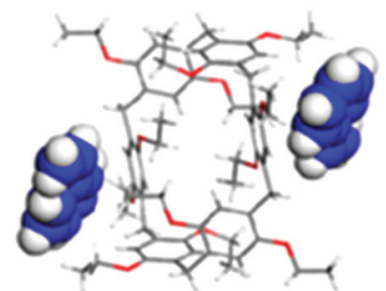

Fig. 26 Single crystal structures of (a) ethylbenzene complexed with EtP5, (b) ethylbenzene complexed with EtP6, (c) styrene complexed with EtP6 in 2D channels between pillararenes. ${ }^{165}$ Reproduced from ref. 165 with permission from the American Chemical Society, copyright 2017.

using a liquid-liquid extraction methodology, achieving a selectivity of over $88 \% .{ }^{169}$

Haloalkanes and haloalkenes are another class of chemicals with great industrial significance as high value feedstocks within the petrochemical and pharmaceutical industries. ${ }^{170}$ Traditionally, these compounds are synthesized through direct halogenation. Due to selectivity issues, this produces reaction mixtures that require complex purification. ${ }^{171}$ To this end, Yang and co-workers report a new class of NACs, desolvated perethylated leaning pillar[6]arenes (EtLP6). This tilted version of the EtP6 scaffold offers enhanced guest binding ability as well as good cavity adaptability, Fig. 27. ${ }^{172}$ Through a similar solid vapour adsorption method as previously reported, ${ }^{168}$ EtLP6 is able to separate the 1-bromo and 2-bromo isomers of bromopropane, bromobutane and bromopentane with $89.6 \%, 93.8 \%$ and $96.3 \%$ purity respectively. ${ }^{173}$ Additionally, the separation of 1-chlorobutane from 2-chlorobutane and vice versa has since been achieved using EtP5 and EtP6 respectively. ${ }^{170}$ As with EtP6, when freed of guests the EtLP6 material may also be reused, and shows no loss of separation ability after being recycled five times.

Moving beyond pillar $[n]$ arenes, Huang and co-workers have also utilized $\mathrm{CB}[6]$, referred to by the authors as $(\mathrm{Q}[6])$, in the formation of NACs, Fig. $28(\mathrm{a}-\mathrm{c}){ }^{174}$ Toluene and pyridine are both important solvents, and are also used in polymer production and for catalysis. The industrial preparation of toluene is often contaminated with pyridine impurities which, similarly to the previous examples, are problematic to remove through distillation. ${ }^{175}$ The authors found that pyridine was
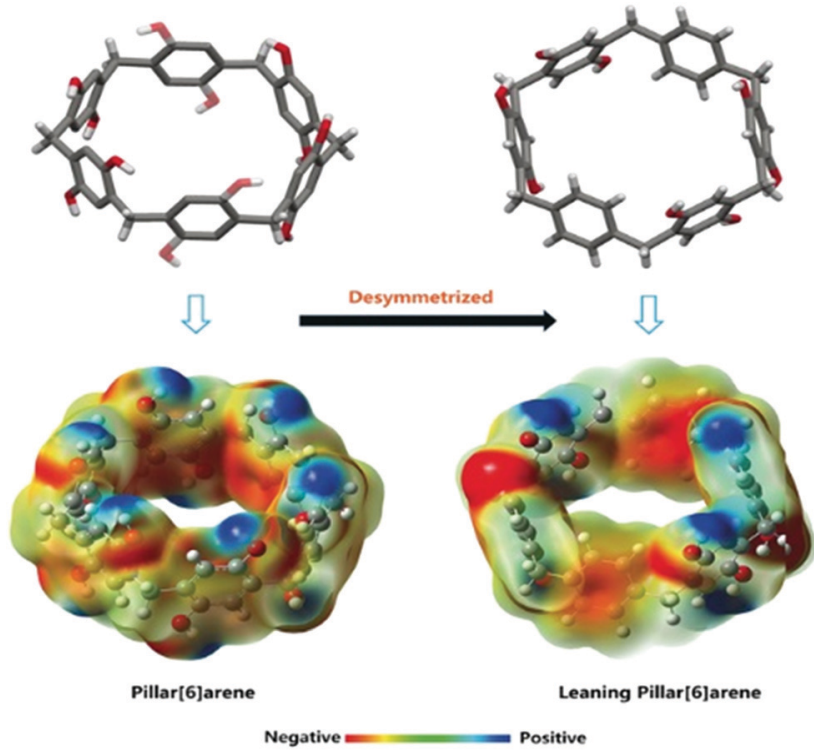

Fig. 27 The structures and potential energy maps of traditional and leaning pillar[6]arenes. ${ }^{172}$ Reproduced from ref. 172 with permission from Wiley, copyright 2018.

capable of forming a host:guest complex with $\mathrm{CB}[6]$, whilst toluene was not. It is as a result of this selective complexation event that this material has been shown to completely remove the pyridine impurities separate from crude toluene, Fig. 28(d).

\section{Supramolecular materials as healable coatings}

Supramolecular materials are constructed using non-covalent forces such as hydrogen bonding, electrostatics and hydrophobic/ hydrophilic interactions. ${ }^{176}$ The reversibility and dynamic nature of these interactions results in the production of materials with unique properties, ${ }^{177}$ capable of responding to temperature, ${ }^{178}$ mechanical stress, ${ }^{179} \mathrm{pH}^{180}$ and the presence of small molecules. ${ }^{5,181,182}$ These materials are often produced through the combination of traditional covalent polymers with functionalities that are capable of binding through supramolecular forces. True supramolecular polymers are those in which the monomers themselves are not polymeric in nature, distinguishing them from supramolecular polymeric hybrid materials. ${ }^{183}$ They were defined by Sijbesma as "polymeric arrays of monomeric units that are brought together by reversible and highly directional secondary interactions, resulting in polymeric properties in dilute and concentrated solutions, as well as in the bulk. The monomeric units of the supramolecular polymers themselves do not possess a repetition of chemical fragments." 184

The reversible nature of supramolecular bonds enables the production of self-healing materials. The term self-healing as used herein, describes materials that, much like a living organism, can repair themselves without any outside intervention. Broadly speaking self-healing materials can be classified into two types: those with the intrinsic ability to heal, ${ }^{185}$ and composite materials containing encapsulated healing agents for triggerable release. ${ }^{186-188}$ In the context of this review, the supramolecular materials discussed herein are those with the inherent ability to 
(a)

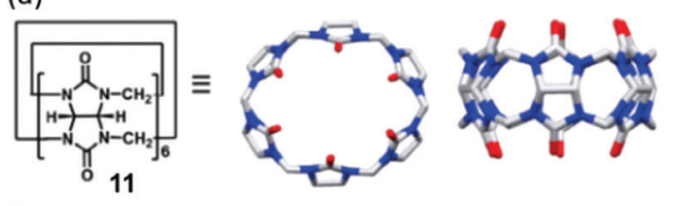

(b)

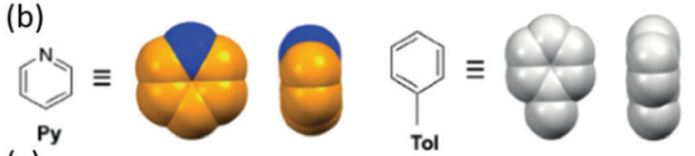

(c)
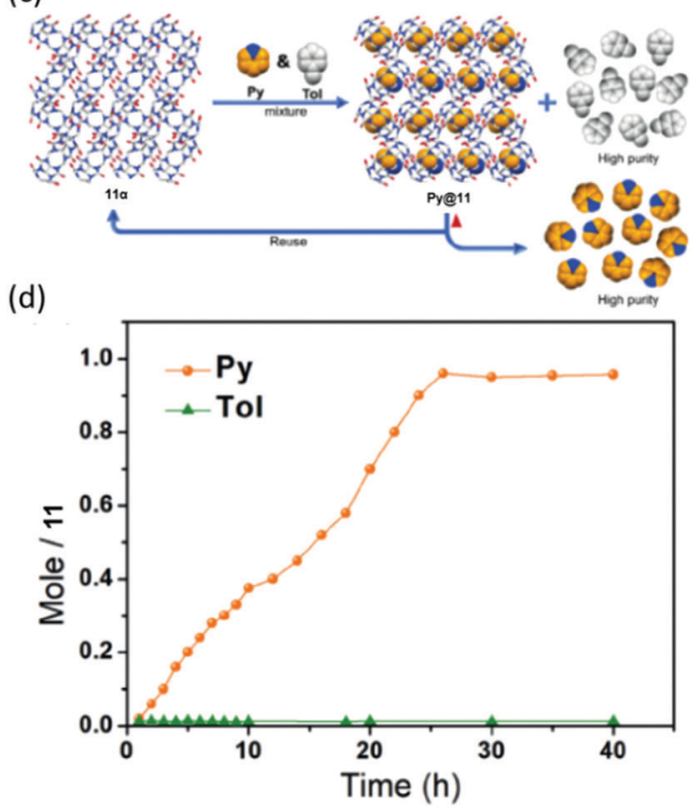

Fig. 28 Chemical structures and cartoon representations of (a) 11 and (b) pyridine and toluene. (c) General scheme showing adsorption and separation of pyridine and toluene by NACs of 11. (d) Time dependent solid-vapour sorption profile for single component pyridine and toluene vapours, reproduced with permission. ${ }^{174}$ Reproduced from ref. 174 with permission from Wiley, copyright 2020.

self-heal. This potential for commercialisation has been realised due to 'maintenance free' properties, leading to the development of these systems as coatings, adhesives and synthetic rubbers.

Coatings are applied to surfaces to protect them from the external environment; however, these coatings often need to be re-applied due to everyday 'wear and tear' degrading surface integrity. Here, supramolecular self-healing materials, developed as protective coatings, offer increased longevity when compared to traditional alternatives such as paints, resins and plastics. ${ }^{189}$ Such traditional materials require manual intervention to remove defects such as scratches, particularly important when considering high value goods. These limitations are not experienced by next-generation supramolecular chemistry inspired alternatives.

Coatings such of this type have already been used in the automotive industry. One example is polyrotaxane paints that have been in used in the car manufacturing industry, specifically by Nissan (since 2005), ${ }^{13}$ to prevent the need for scratch repair on vehicles. The same manufacturer has also expanded the applications of this technology, producing a self-healing smartphone case, reported to be able to fix minor abrasions in under an hour. Working with mobile operator NTT DoCoMo, and with Advanced Softmaterials Inc., a University of Tokyo based company, Nissan also aims to incorporate this class of materials directly into the production of the next generation of smartphones. ${ }^{13}$

Rotaxanes are a class of interlocked molecules, featuring the general structure shown in Fig. 29. ${ }^{190}$ Polyrotaxanes, a sub-class of the rotaxane family, feature a single molecular axle that passes through multiple macrocycles. They have been extensively studied by 2016 Nobel Prize winning chemists Stoddart and Sauvage. 9,191 The polyrotaxane macrocycles are free to move along the molecular axle due to the lack of covalent bonding between the two, and it is this property that gives rise to their potential commercial material applications. ${ }^{192}$ Due to the popularity of these systems, multiple comprehensive reviews have been published on the synthesis, properties and potential applications of these compounds. ${ }^{192-194}$

An example highlighting the application of polyrotaxanes in the production of supramolecular self-healing materials is provided by Harada and co-workers, Fig. 30. This work shows how supramolecular rotaxane systems can be combined with dynamic covalent bonds ${ }^{195}$ to produce materials that can selfheal through both physical (supramolecular) and chemical (dynamic covalent chemistry) mechanisms. Here, the supramolecular 'mechanical bond' allows the physical movement of cyclodextrin macrocycles along their axle to compensate for external stress, while the dynamic covalent bonds can break and reform at new positions, healing the material to a greater degree of strength.

This combination of dynamic covalent and supramolecular chemistry was initially utilised in the development of supramolecular gels, giving rise to systems that when physically split in two, could be re-joined to recover $83 \%$ of the original sample strength in only five minutes. ${ }^{15}$ The recovery of material strength in this instance is attributed to the dynamic nature of the boronic acid-diol bond, a feature that has seen their use in an ever-increasing number of functional materials. ${ }^{6,196}$ As exemplified by Harada, material self-healing is a common attribute in wet materials such as hydrogels. However, further development of this dynamic covalent-supramolecular system

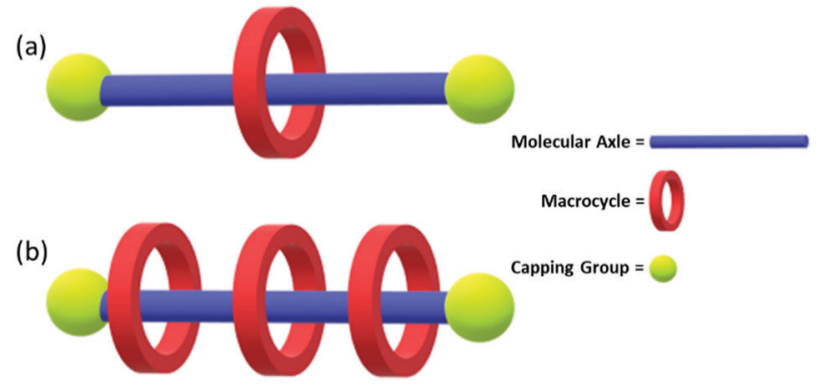

Fig. 29 (a) Rotaxane molecule featuring a molecular axle threaded through a macrocycle held in place by a capping group. (b) A polyrotaxane featuring multiple macrocycles. 
(a)

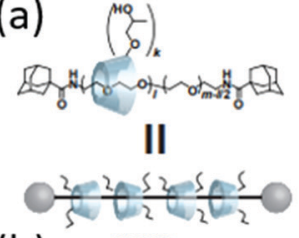

(b)
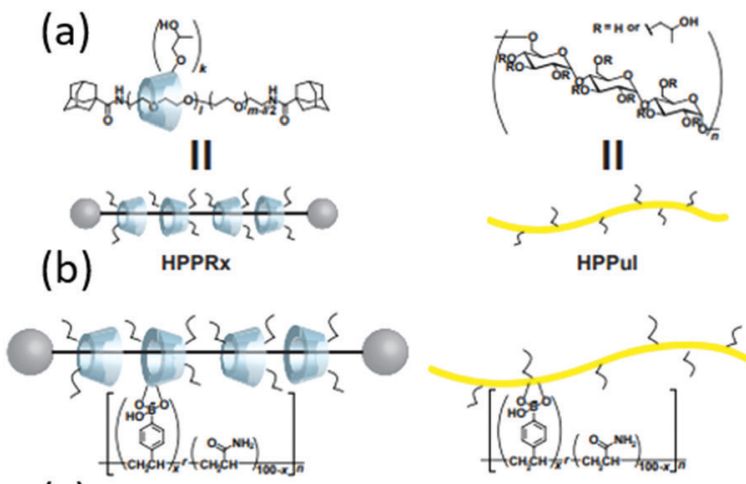

(c)
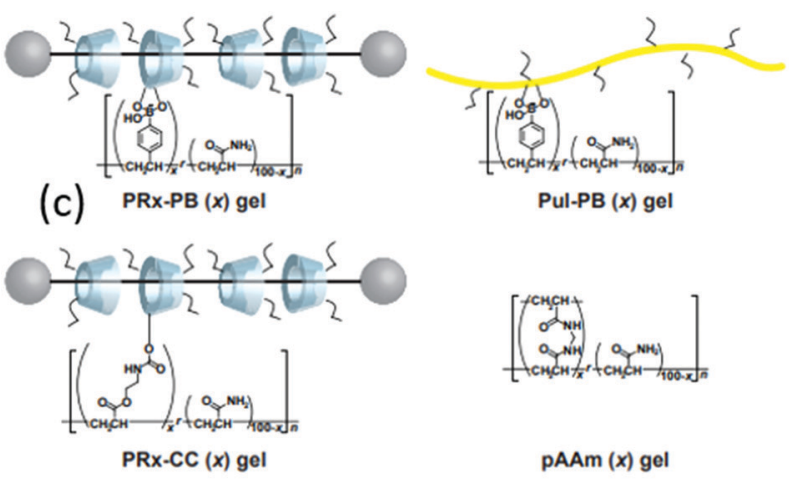

pAAm $(x)$ gel

\section{Physical Self-healing}

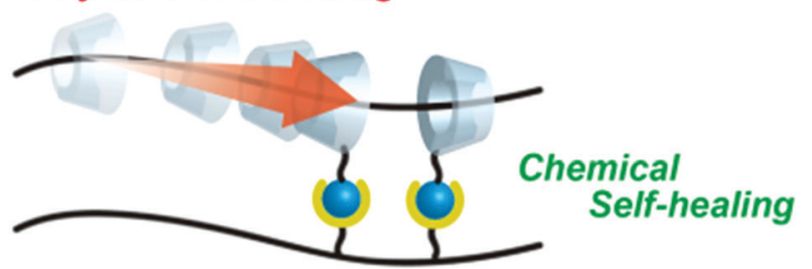

Fig. 30 (a) Schematic representation of cyclodextrin/polyacrylamide polyrotaxane system used by Harada et al. (b) The chemical structures of: the polyrotaxane-boronic acid hybrid gel (PRx-PB), the boronic acid containing polyacrylamide-cyclodextrin gel (Pul-PB), covalently bound cyclodextrin-polyacrylamide gel (PRx-CC) and polyacrylamide gels (pAAm). (c) The combination of dynamic chemical and physical bonds that allow efficient self-healing. ${ }^{15}$ Reproduced from ref. 15 with permission from Cell Press, copyright 2016.

has allowed for a step-change toward also achieving this selfhealing functionality within dry materials. This has classically been problematic, due to the decreased diffusivity inherent in systems that are not associated with a solvent. The addition of a commercially available photoinitiator (in this case Irgacure 2959), and subsequent exposure of the mixture to UV light, enabled the polyrotaxane-boronate system to become further crosslinked, resulting in the production of a scratch healable coating that can be applied to hard surfaces.

Here glass slides were coated with three variations of these materials PRx-PB, PuI-PB and PRx-CC materials. An incision was then made through the coating, to expose the glass underneath, and the self-healing ability of the coating was then observed, Fig. 31(a). The dual supramolecular-dynamic covalent physical-chemical healing properties of PRx-PB coating offered full material recovery within 30 minutes. The coatings lacking either supramolecular (PuI-PB) or dynamic covalent (PuI-CC) properties did demonstrate self-healing properties however, these offered a much lower performance over the same 30 minute time frame, Fig. 31(b). (a)
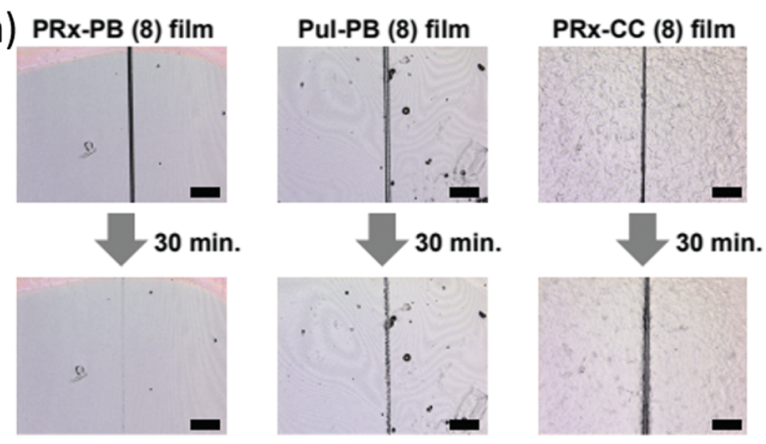

(b)

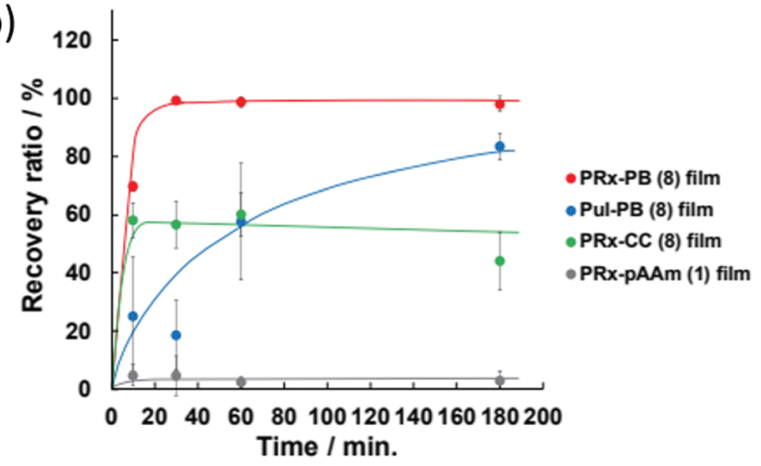

Fig. 31 (a) The self-healing abilities of films containing rotaxanes crosslinked with dynamic boronic acid bonds (PRx-PB), films offering dynamic boronic acid bonds without the additional physical recovery due to rotaxane movement (Pul-PB), and films containing rotaxanes covalently bound to the polyacrylamide backbone (PRx-CC). (b) The recovery ratio versus time of each of the previously described materials, as well as polyrotaxanes with neither dynamic nor covalent crosslinkers (PRxpAAm) ${ }^{15}$ Reproduced from ref. 15 with permission from Cell Press, copyright 2016.

\section{Self-healing rubbers}

Rubbers are a 'dry' polymer with numerous applications worldwide from automobile fixtures and fittings to pencil erasers, and have an estimated global market value of 31.3 billion dollars (2019), which is predicted to increase. ${ }^{197}$ However, these materials suffer from poor longevity, lack of re-processability, and have a heavy environmental impact. Here, we showcase the efforts of supramolecular chemists to develop rubbers that are self-healing, and therefore exhibit longer useful lifetimes. Some of the described supramolecular rubbers can be recycled, resulting in the production of materials that act as a greener alternative to traditional systems. Practical applications of such supramolecular rubbers would be varied; it is easy to imagine that such technology would allow for the development of selfhealing tyres with the potential to reduce automotive accidents, and decrease reducing upkeep costs. ${ }^{198}$

As previously mentioned, materials that exhibit self-healing properties in dry conditions are more challenging to develop. The lack of co-solvents makes this process problematic as the production of supramolecular rubbers often involves the combination of non-covalent, reversible (often polar) and covalent (often non-polar) crosslinkers. ${ }^{199}$ Weitz et al. report the use of randomly branched polymers, containing motifs capable of acting as both reversible supramolecular and 

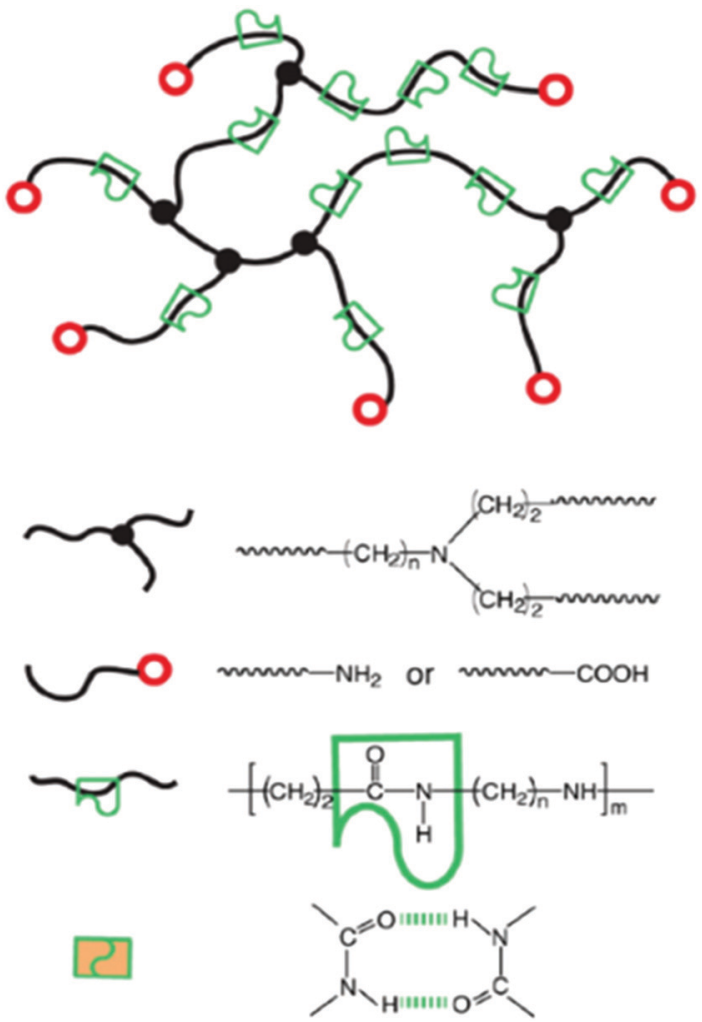

Fig. 32 Schematic representation of the hybrid elastomer produced by Weitz et al. Reproduced with permission. ${ }^{16}$ Reproduced from ref. 16 with permission from Wiley, copyright 2017.

covalent crosslinkers (Fig. 32), generating a self-healing hybrid elastomer that exhibited a fracture energy of $13500 \mathrm{~J} \mathrm{~m}^{-2}$, which is comparable to natural rubber. ${ }^{16}$

To develop this material towards commercial applications, Weitz et al. reacted diamine and acrylic acid monomeric units, to generate randomly branched polymers consisting of monosubstituted, di-substituted and tri-substituted amides. The unreacted, pre-polymer, monomeric mixture is a viscous liquid, which can be poured/injected into a mould. On heating the mixture above $150{ }^{\circ} \mathrm{C}$, condensation reactions occur between the amine and carboxyl groups contained within the monomeric units, resulting in covalent crosslinks, which secure a three-dimensional network that can maintain the shape of a mould. The ease by which this material can be formed into specific shapes has advantages when considering material manufacture for a variety of potential applications. The selfhealing properties of this class of materials arises from the presence of the secondary amide groups, produced from the reactions of these monomeric units. Here the amide groups act as both hydrogen bond donors and acceptors, further stabilising the structure of the material through the formation of multiple hydrogen bonds (Fig. 32).

Within this material small deformations can be self-healed though the reformation of reversible amide-amide hydrogen bond however, larger deformations that result in the breaking of covalent bonds yield non-reversible material damage. ${ }^{200}$
In this combination approach, only the reversible hydrogen bonds can reform, therefore the material only recovers $30 \%$ of its mechanical strength when stretched beyond the limit of the covalent crosslinks.

Butyl rubber is a commonly used synthetic substitute for natural rubber and is produced from the reaction of isobutylene and isoprene. The inclusion of alkyl halides into butyl rubber has been found to increase material crosslinking efficacy, when incorporating agents such as sulfur and epoxides. ${ }^{201}$ In line with material developments in this area, Heinrich et al. have developed a simple methodology for the conversion of the widely used bromobutyl material into a selfhealing rubber. Here, as shown in Fig. 33, the introduction of butylimidazole groups (34) allowed the material to crosslink with ionic bonds, rather than covalent. The incorporation of reversible supramolecular bonds, resulted in a material capable of self-healing. ${ }^{198}$

The introduction of ionic interactions into the covalent bromobutyl rubber network negates the need for further additives such as sulphur or peroxides, yielding a material with an elastic modulus superior to that of conventional rubbers. ${ }^{201}$

The tensile strength of this butylimidazole incorporated bromobutyl rubber was found to be greater than of the conventional sulphur crosslinked bromobutyl rubber ( 9 and 8 MPa respectively). In addition, when comparing the stretchability of both materials, the supramolecular system again outperformed the conventional sulfur system $(1000 \%$ and $\approx 800 \%$ stretchability respectively). As can be seen in Fig. 34, the reversible nature of the ionic interactions within this material is able to facilitate molecular rearrangement, allowing separate pieces of the material to be re-joined. Further alteration of the materials molecular structure (varying the $n$-alkyl chain length) has led to the identification of a distinct correlation between alkyl chain mobility and self-healing properties. Extending this approach, Böhme et al. have demonstrated that the mechanical properties of these materials may also be tuned through an alteration of chain length. ${ }^{202}$

The re-processability of covalently crosslinked rubbers is limited, due to the complex and energy intensive processes involved. ${ }^{203}$ In an effort to overcome this limitation, Böhme et al. introduced complimentary hydrogen bond donating and

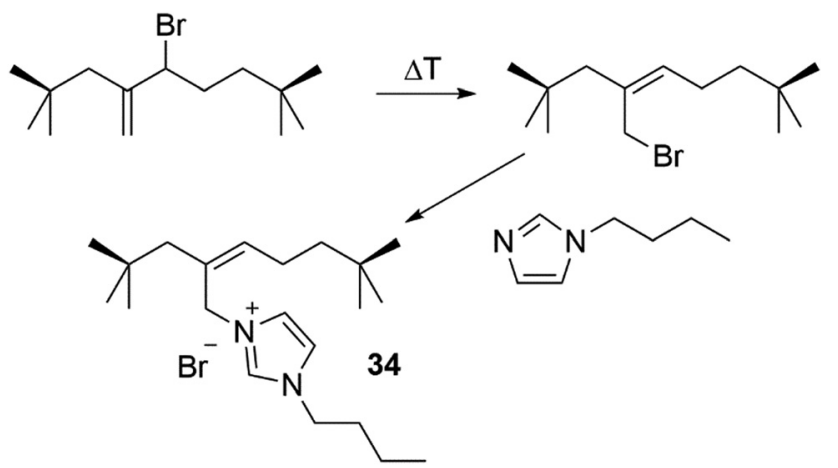

Fig. 33 The introduction of butylimidazole groups into bromobutyl rubber, yielding groups able to crosslink rubbers through ionic bonds. 
(a)

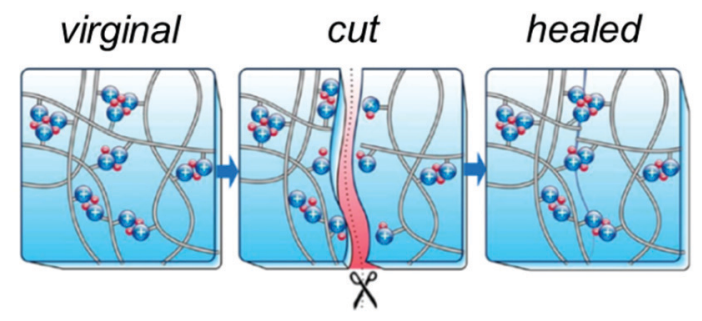

(b)

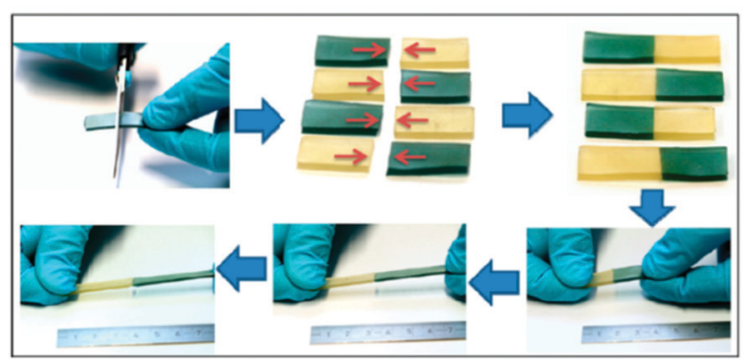

Fig. 34 (a) The movement of charge clusters allowing reformation of the material. (b) The self-healing nature of the material, demonstrated by the use of coloured dye. ${ }^{198}$ Reproduced from ref. 198 with permission from the American Chemical Society, copyright 2015.

accepting moieties into the molecular structure of the butyl rubber material, resulting in the incorporation of secondary supramolecular binding modes, in addition to the ionic interactions previously discussed, 35 (Fig. 35(a)). ${ }^{204}$ This incorporation of complimentary hydrogen bond donating and accepting functionalities allows the material to be re-processed through the implementation of a heating-cooling process annealing process, to allow the reformation of the hydrogen bonding network, which allows the material to be reused (Fig. 35(b)). ${ }^{204}$ This innovation represents a plausible route towards the development of green alternatives for covalently crosslinked rubbers, which as

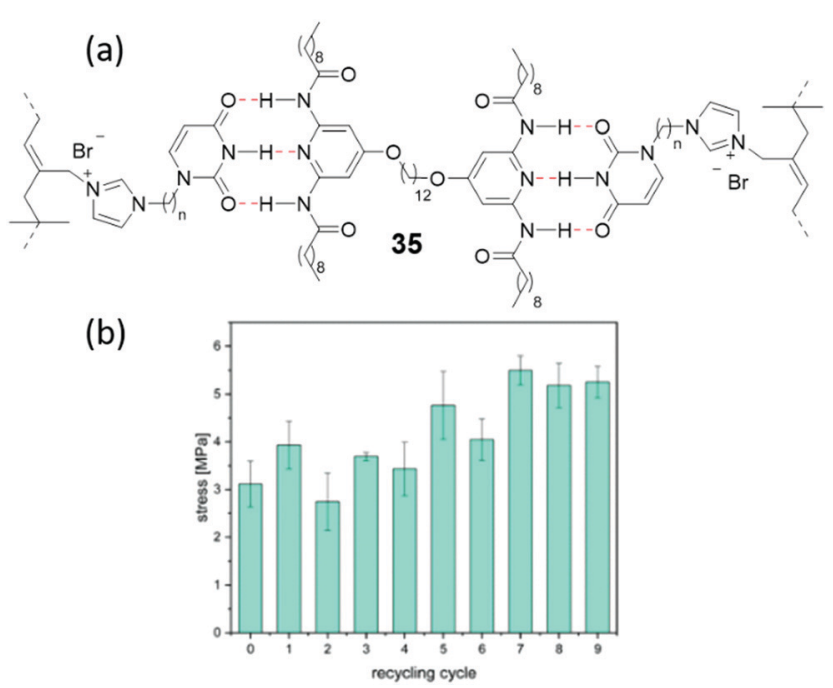

Fig. 35 (a) lonically modified butyl rubber doped with uracil (35) to give hydrogen bonding interactions; red dotted lines indicate hydrogen bonding. (b) Stress at break values after 9 reprocessing cycles. ${ }^{204}$ Reproduced from ref. 204 with permission from the Royal Society of Chemistry, copyright 2020 . thermosetting materials cannot be softened or remoulded for future uses. ${ }^{203}$

\section{Supramolecular chemistry towards the development of adhesives for use in humid environments}

The application of supramolecular chemistry in the development of traditional adhesives has already been discussed, however recent advances in material development have also led to the creation of a 'velcro'-like material, capable of reversible adhesion underwater. ${ }^{205}$ Such materials have a wide variety of uses in moist environments, such as the repair of leaks in piping, the fixing of ordnance and beacons to surfaces, as well as in a surgical setting. ${ }^{206}$ However, creating materials capable of bonding underwater is challenging, due to the interference of water at the interface between the adhesive and adhered surfaces. The presence of water molecules at the interface inhibits adhesivesurface contact, and thus prevents efficient fastening. ${ }^{207}$

Previous attempts to develop such materials have often looked to nature for inspiration. Mussels, barnacles and other sea dwelling species produce natural adhesives that can bind strongly despite the aqueous environments. ${ }^{206,208}$ This property arises from the increase prevalence of catechol containing 3,4dihydroxyl-L-phenylalanine (DOPA) residues within the protein adhesives that these aquatic species secrete. This has led to the production of a number of catechol containing biomimetic underwater adhesive polymers. ${ }^{209,210}$ These adhesive materials have been explored in great detail and have been extensively reviewed. ${ }^{211-213} \mathrm{~A}$ limiting factor of the catechol containing adhesives produced to date is their inability to act as reversible bonding agents. Further to this, curing agents must be added to complete the adhesion processes ${ }^{214}$ which can be problematic for certain applications. Kim et al. took a purely synthetic route in their approach to the development of a 'supramolecular velcro' adhesive. The formation of host-guest supramolecular complexes in aqueous solutions is accompanied by expulsion of water molecules from hydrophobic host cavities. ${ }^{215}$ One such host-guest pairing, uses $\mathrm{CB}[7]$ as the host and aminomethylferrocene as the guest, complexation between the host and guest results in a $K_{\mathrm{a}} \approx 10^{12} \mathrm{M}^{-1}$. ${ }^{216}$ Here, the host $\mathrm{CB}[7]$ was bound to one surface to be adhered, and aminomethylferrocene was bound to the second, Fig. 36 . When the two surfaces are brought together, complexation occurs between the host and guest, driven entropically by the expulsion of water from the hydrophobic cavity.

The strength of this supramolecular adhesive was found to be greater than that of commercial alternatives $\left(3 \mathrm{M}^{\mathrm{TM}}\right.$ Velcro, $3 \mathrm{M}^{\mathrm{TM}}$ double sided tape and $3 \mathrm{M}^{\mathrm{TM}}$ double sided foam tape), when tested both in air and underwater. Similarly, when compared to previously reported mollusc inspired adhesive polymers, this material displayed similar adhesive strengths, without the need for curing agents (mussel derived adhesion strength: $1.5 \mathrm{MPa}^{217}$ and $1.2 \mathrm{MPa} ;{ }^{218} \mathrm{CB}[7]$ adhesion strength: $1.12 \mathrm{MPa}) .{ }^{207}$

It was possible to tune the strength of adhesion for the $\mathrm{CB}[7] /$ aminomethylferrocene 'velcro' by varying the density of the host and guest molecules present on the separate surfaces. 


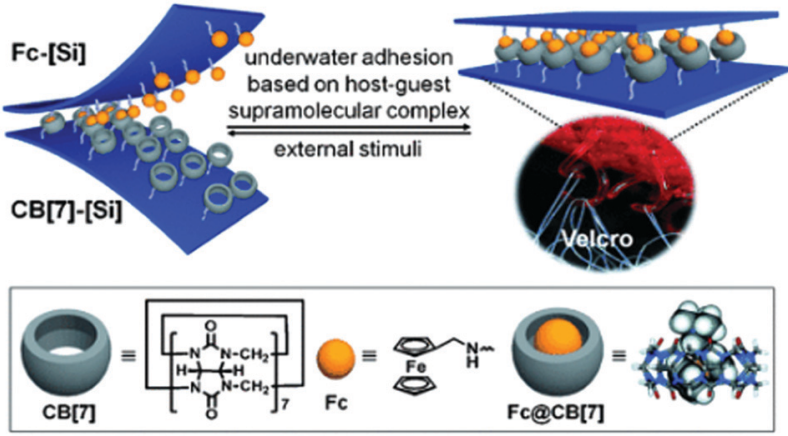

Fig. 36 A schematic representation of the CB[7]/aminomethylferrocene 'velcro', with a light microscope image of traditional hook and loop Velcro. ${ }^{205}$ Reproduced from ref. 205 with permission from Wiley, copyright 2013.

Much like conventional velcro, this adhesion of the $\mathrm{CB}[7] /$ aminomethylferrocene 'velcro' was reversible when broken mechanically, owing to its self-healing ability obtained through reversible complexation events. The adhesive bond of the material was also chemically switchable, thanks to the redoxactive nature of the aminomethylferrocene. On immersion of the aminomethylferrocene surface in a $10 \mathrm{mM}$ solution of $\mathrm{NaClO}$, the oxidation of the aminomethylferrocene turned off the adhesion, as the oxidised species no longer acts as an effective guest. ${ }^{219}$ The guest surface was found to be reactivated through exposure to ascorbic acid (20 mM) however, this only resulted in $44 \%$ of the original adhesive strength. ${ }^{205}$

Adhesives, both supramolecular and traditional, are often polymeric in nature. These include resins, bioadhesive gels and all previously discussed systems. In contrast, low molecular weight monomeric units as adhesives have received limited interest in the field, with few systems having been reported. ${ }^{220}$ One example of such a system was produced by Dong and co-workers, who developed a crown-ether containing, low molecular weight supramolecular adhesive, 36, capable of tough and stable adhesion of a range of materials in seawater over periods of twelve months, Fig. $37 . .^{221}$ This novel material was able to bind to both hydrophobic (PTFE and Teflon) and hydrophilic materials (steel and glass). This is thought to be due to a combination of the large range of supramolecular interactions that it can form, including hydrogen bonds,

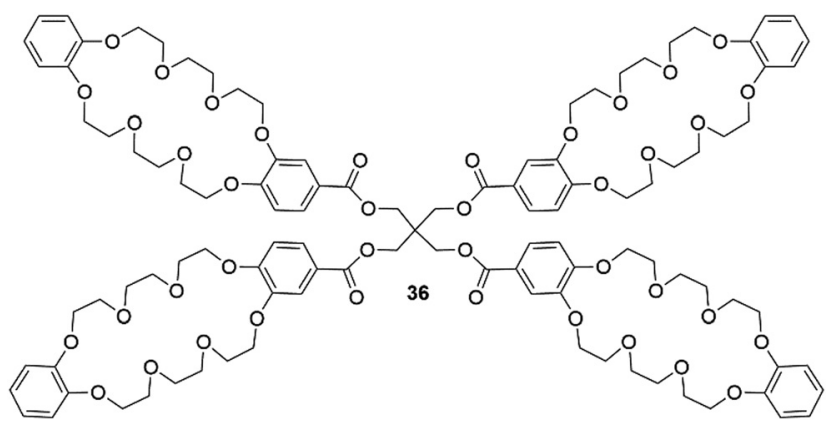

Fig. 37 Structure of small molecular weight supramolecular adhesive developed by Dong et al.

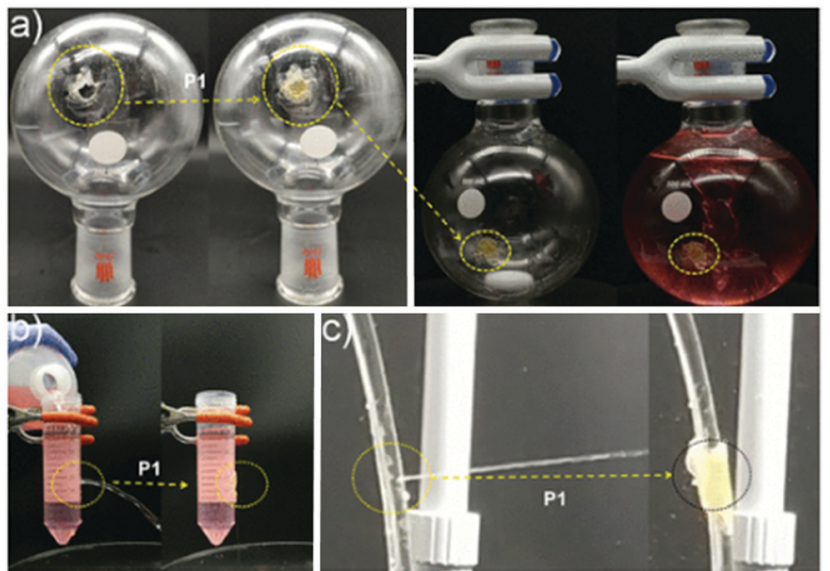

Fig. 38 Compound 22 fixing and making watertight (a) a broken glass round bottom flask, (b) a centrifuge tube and (c) a water pipe. ${ }^{221}$ Reproduced from ref. 221 with permission from the American Chemical Society, copyright 2020 .

electrostatic forces, $\pi-\pi$ stacking, hydrophobic interactions and metal complexation. Here, similar adhesive strengths (1.94 $\mathrm{MPa}$ compared to $2.02 \mathrm{MPa}$ ) could be achieved with almost ten times less material $\left(1.25 \mathrm{mg} \mathrm{cm}^{-2}\right.$ compared to $11.6 \mathrm{mg} \mathrm{cm} \mathrm{cm}^{-2}$ ). Furthermore, to prepare a $20 \mathrm{~cm}^{2}$ area of this adhesive by hand required an hour however, it was found that this same area could also be prepared through electrospinning in just one minute. The versatility of this material has been shown through real life testing in which it has been used as a patch (Fig. 38) to repair breakages in glass flasks, plastic centrifuge tubes and water pipes.

\section{Supramolecular chemistry in battery materials}

As previously discussed, polyrotaxane based materials offer unique physical properties. The 'sliding' of the macrocycles along a molecular axle allows them to efficiently dissipate energy. This has sparked investigation into their use as binder materials in lithium ion batteries. The use of silicon particles as an anode material in these batteries shows great promise, however during charge-discharge cycles the silicon undergoes large volume changes, resulting in particle destruction. ${ }^{222}$ Elastic materials are thus added to prevent this effect, traditionally this material is polyacrylic acid. Choi and co-workers have shown that with the addition of $5 \% \mathrm{w} / \mathrm{w}$ polyrotaxane to the binder material, the elasticity is greatly increased. ${ }^{223}$ The inclusion abilities of this supramolecular motif has yielded a material capable of increasing the lifetime of these high capacity batteries to commercially viable levels.

\section{Conclusions}

The varied and unique properties that the application of supramolecular chemistry can bring to products is only now being realised. Huge leaps in host guest chemistries are paving the way towards more accurate real time glucose sensors, previously dangerous chemical warfare agent disposal is being 
made safe through the use of gels, and soon a punctured tyre may be capable of simply repairing itself. This is by no means an exhaustive list of the expansive research occurring within supramolecular chemistry with great potential for commercialisation, and work continues in many groups that will yield even more impressive materials, sensors and other applicationsbased chemistries. We hope that by highlighting a range of areas in which supramolecular chemistry has moved out of the lab and into the real world, we may inspire others to make this transition with their own scientific endeavours.

\section{Conflicts of interest}

There are no conflicts to declare.

\section{Acknowledgements}

GTW would like to thank the University of Kent GCDC for funding his postdoctoral fellowship. JRH would like to thank the UKRI for her Future Leaders Fellowship funding (MR/ T020415/1). MF and PAG acknowledge and pay respect to the Gadigal people of the Eora Nation, the traditional owners of the land on which we research, teach and collaborate at the University of Sydney. MF thanks the University of Sydney for funding. PAG thanks the Australian Research Council (DP180100612, DP200100453 and LE210100144) and the University of Sydney for funding. CJEH thanks University College London for financial support.

\section{Notes and references}

1 J. M. Lehn, Acc. Chem. Res., 1978, 11, 49-57.

2 C. R. Patrick and G. S. Prosser, Nature, 1960, 187, 1021.

3 D. M. G. Lawrey and H. McConnell, J. Am. Chem. Soc., 1952, 74, 6175-6177.

4 W. G. Levine and J. Peisach, Nature, 1965, 207, 406-407.

5 E. V. Lampard, A. C. Sedgwick, T. Sombuttan, G. T. Williams, B. Wannalerse, A. T. A. Jenkins, S. D. Bull and T. D. James, ChemistryOpen, 2018, 7, 266-268.

6 G. T. Williams, A. C. Sedgwick, S. Sen, L. Gwynne, J. E. Gardiner, J. T. Brewster, J. R. Hiscock, T. D. James, A. T. A. Jenkins and J. L. Sessler, Chem. Commun., 2020, 56, 5516-5519.

7 B. C. Crane, N. P. Barwell, P. Gopal, M. Gopichand, T. Higgs, T. D. James, C. M. Jones, A. Mackenzie, K. P. Mulavisala and W. Paterson, J. Diabetes Sci. Technol., 2015, 9, 751-761.

8 https://www.nobelprize.org/prizes/chemistry/1987/press-release/, (accessed 28/07/20).

9 https://www.nobelprize.org/prizes/chemistry/2016/summary/ $\% 3 \mathrm{E}$, (accessed 27/05/20).

10 J. M. Lehn, Chem. Soc. Rev., 2017, 46, 2378-2379.

11 T. Trinh, J. P. Cappel, P. A. Geis, M. L. McCarty, D. Pilosof and S. S. Zwerdling, US Pat., US5714137, 1998.
12 J. K. Tusa and H. R. He, J. Mater. Chem., 2005, 15, 2640-2647.

13 https://europe.nissannews.com/en-GB/releases/release-87812world-s-first-self-healing-iphone-case, (accessed 30/06/20).

14 A. P. de Silva and K. R. A. S. Sandanayake, J. Chem. Soc., 1989, 1183-1185.

15 M. Nakahata, S. Mori, Y. Takashima, H. Yamaguchi and A. Harada, Chem, 2016, 1, 766-775.

16 J. R. Wu, L. H. Cai and D. A. Weitz, Adv. Mater., 2017, 29, 8.

17 D. Jagleniec, L. Dobrzycki, M. Karbarz and J. Romanski, Chem. Sci., 2019, 10, 9542-9547.

18 N. J. Williams, C. A. Seipp, K. A. Garrabrant, R. Custelcean, E. Holguin, J. K. Keum, R. J. Ellis and B. A. Moyer, Chem. Commun., 2018, 54, 10048-10051.

19 I. V. Kolesnichenko and E. V. Anslyn, Chem. Soc. Rev., 2017, 46, 2385-2390.

20 F. Arnaudneu, E. M. Collins, M. Deasy, G. Ferguson, S. J. Harris, B. Kaitner, A. J. Lough, M. A. McKervey, E. Marques, B. L. Ruhl, M. J. Schwingweill and E. M. Seward, J. Am. Chem. Soc., 1989, 111, 8681-8691.

21 M. A. McKervey, D. P. Melody, J. Woods and J. M. Rooney, Eur. Pat., EP0151527A1, 1984.

22 J. Szejtli, Chem. Rev., 1998, 98, 1743-1754.

23 G. Crini, Chem. Rev., 2014, 114, 10940-10975.

24 A. Haimhoffer, A. Rusznyak, K. Reti-Nagy, G. Vasvari, J. Varadi, M. Vecsernyes, I. Bacskay, P. Feher, Z. Ujhelyi and F. Fenyvesi, Sci. Pharm., 2019, 87, 21.

25 M. E. Davis and M. E. Brewster, Nat. Rev. Drug Discovery, 2004, 3, 1023-1035.

26 S. B. Carneiro, F. Í. Costa Duarte, L. Heimfarth, J. d. S. Siqueira Quintans, L. J. Quintans-Júnior, V. F. d. Veiga Júnior and Á. A. Neves de Lima, Int. J. Mol. Sci., 2019, 20, 642.

27 C. Muankaew and T. Loftsson, Basic Clin. Pharmacol. Toxicol., 2018, 122, 46-55.

28 O. Adeoye and H. Cabral-Marques, Int. J. Pharm., 2017, 531, 521-531.

29 J. R. Lakkakula and R. W. Macedo Krause, Nanomedicine, 2014, 9, 877-894.

30 T. Loftsson, J. Inclusion Phenom. Macrocyclic Chem., 2002, 44, 63-67.

31 P. Jansook, G. C. Ritthidej, H. Ueda, E. Stefánsson and T. Loftsson, J. Pharm. Pharm. Sci., 2010, 13, 336-350.

32 A. Ohira, K. Hara, G. Jóhannesson, M. Tanito, G. M. Ásgrímsdóttir, S. H. Lund, T. Loftsson and E. Stefánsson, Acta Ophthalmol., 2015, 93, 610-615.

33 G. Johannesson, M. D. Moya-Ortega, G. M. Asgrimsdottir, S. H. Lund, M. Thorsteinsdottir, T. Loftsson and E. Stefansson, Acta Ophthalmol., 2014, 92, 550-556.

34 S. A. Oculis, 2020, https:/www.globenewswire.com/newsrelease/2020/02/10/1982307/0/en/Oculis-Announces-PositiveOCS-01-Phase-2-Data-in-Patients-with-Diabetic-Macular-EdemaDME.html, (accessed 29/10/2020).

35 K. Imamachi, E. Stefansson, A. Ohira and M. Tanito, Acta Ophthalmol., 2019, 97, 824-827.

36 J. S. Krinsley, M. Egi, A. Kiss, A. N. Devendra, P. Schuetz, P. M. Maurer, M. J. Schultz, R. T. van Hooijdonk, 
M. Kiyoshi, I. M. Mackenzie, D. Annane, P. Stow, S. A. Nasraway, S. Holewinski, U. Holzinger, J. C. Preiser, J. L. Vincent and R. Bellomo, Crit. Care, 2013, 17, R37.

37 Y. Mamo, F. Bekele, T. Nigussie and A. Zewudie, BMC Endocr. Disord., 2019, 19, 91.

38 D. C. Klonoff, D. Ahn and A. Drincic, Diabetes Res. Clin. Pract., 2017, 133, 178-192.

39 A. Wood, D. O’Neal, J. Furler and E. I. Ekinci, Intern. Med. J., 2018, 48, 499-508.

40 J. P. Lorand and J. O. Edwards, J. Org. Chem., 1959, 24, 769-774.

41 G. Wulff, Pure Appl. Chem., 1982, 54, 2093-2102.

42 H. Fang, G. Kaur and B. Wang, J. Fluoresc., 2004, 14, 481-489.

43 Z. Guo, I. Shin and J. Yoon, Chem. Commun., 2012, 48, 5956-5967.

44 X. Sun, B. M. Chapin, P. Metola, B. Collins, B. Wang, T. D. James and E. V. Anslyn, Nat. Chem., 2019, 11, 768-778.

45 O. Hirata, Y. Kubo, M. Takeuchi and S. Shinkai, Tetrahedron, 2004, 60, 11211-11218.

46 W. Yang, S. Gao, X. Gao, V. V. R. Karnati, W. Ni, B. Wang, W. B. Hooks, J. Carson and B. Weston, Bioorg. Med. Chem. Lett., 2002, 12, 2175-2177.

47 L. Zhu, S. H. Shabbir, M. Gray, V. M. Lynch, S. Sorey and E. V. Anslyn, J. Am. Chem. Soc., 2006, 128, 1222-1232.

48 T. D. James, K. R. A. S. Sandanayake and S. Shinkai, J. Chem. Soc., Chem. Commun., 1994, 4, 477-478.

49 W. Ni, G. Kaur, G. Springsteen, B. Wang and S. Franzen, Bioorg. Chem., 2004, 32, 571-581.

50 S. Arimori, M. L. Bell, C. S. Oh and T. D. James, Org. Lett., 2002, 4, 4249-4251.

51 S. Arimori, M. L. Bell, C. S. Oh, K. A. Frimat and T. D. James, Chem. Commun., 2001, 1836-1837.

52 S. Arimori, M. L. Bell, C. S. Oh, K. A. Frimat and T. D. James, J. Chem. Soc., Perkin Trans. 1, 2002, 803-808.

53 M. Mortellaro and A. DeHennis, Biosens. Bioelectron., 2014, 61, 227-231.

54 B. C. Crane, N. P. Barwell, P. Gopal, M. Gopichand, T. Higgs, T. D. James, C. M. Jones, A. Mackenzie, K. P. Mulavisala and W. Paterson, J. Diabetes Sci. Technol., 2015, 9, 751-761.

55 T. D. James, 2019, https://chemistrycommunity.nature.com/ posts/53695-measure-for-measure-fluorescent-boronic-acidsensors-for-continuous-monitoring-of-glucose-based-on-orthoaminomethylphenylboronic-acids-an-ongoing-shakespeariandrama, (accessed 29/10/2020).

56 T. D. James, K. R. A. S. Sandanayake and S. Shinkai, Angew. Chem., Int. Ed. Engl., 1994, 33, 2207-2209.

57 T. D. James, K. S. Sandanayake, R. Iguchi and S. Shinkai, J. Am. Chem. Soc., 1995, 117, 8982-8987.

58 A. E. Colvin and H. Jiang, J. Biomed. Mater. Res., Part A, 2013, 101, 1274-1282.

59 W. Freeman, W. Mock and N. Shih, J. Am. Chem. Soc., 1981, 103, 7367-7368.

60 S. J. Barrow, S. Kasera, M. J. Rowland, J. del Barrio and O. A. Scherman, Chem. Rev., 2015, 115, 12320-12406.
61 R. S. Cicolani, L. R. R. Souza, G. B. de Santana Dias, J. M. R. Gonçalves, I. d. S. Abrahao, V. M. Silva and G. J. F. Demets, J. Inclusion Phenom. Macrocyclic Chem., 2020, DOI: 10.1007/s10847-020-00999-8.

62 G. Stephenson, R. M. Parker, Y. Lan, Z. Yu, O. A. Scherman and C. Abell, Chem. Commun., 2014, 50, 7048-7051.

63 D. Das, K. I. Assaf and W. M. Nau, Front. Chem., 2019, 7, 619.

64 S. K. Konda, R. Maliki, S. McGrath, B. S. Parker, T. Robinson, A. Spurling, A. Cheong, P. Lock, P. J. Pigram and D. R. Phillips, ACS Med. Chem. Lett., 2017, 8, 538-542.

65 J. Kim, I.-S. Jung, S.-Y. Kim, E. Lee, J.-K. Kang, S. Sakamoto, K. Yamaguchi and K. Kim, J. Am. Chem. Soc., 2000, 122, 540-541.

66 X. M. Chen, Y. Chen, Q. Yu, B. H. Gu and Y. Liu, Angew. Chem., Int. Ed., 2018, 57, 12519-12523.

67 H. Qiao, J. Jia, W. Chen, B. Di, O. A. Scherman and C. Hu, Adv. Healthcare Mater., 2019, 8, 1801458.

68 R. A. Bissell and A. P. De Silva, J. Chem. Soc., Chem. Commun., 1991, 1148-1150.

69 A. J. Bryan, A. P. de Silva, S. A. De Silva, R. A. D. D. Rupasinghe and K. R. A. S. Sandanayake, Biosensors, 1989, 4, 169-179.

70 M. Y. Chae and A. W. Czarnik, J. Am. Chem. Soc., 1992, 114, 9704-9705.

71 A. P. De Silva and H. Q. N. Gunaratne, J. Chem. Soc., Chem. Commun., 1990, 186-188.

72 P. A. De Silva, N. H. Q. Gunaratne and C. P. McCoy, Nature, 1993, 364, 42-44.

73 M. E. Huston, E. U. Akkaya and A. W. Czarnik, J. Am. Chem. Soc., 1989, 111, 8735-8737.

74 J. Yoon and A. W. Czarnik, J. Am. Chem. Soc., 1992, 114, 5874-5875.

75 A. P. De Silva, T. P. Vance, M. E. S. West and G. D. Wright, Org. Biomol. Chem., 2008, 6, 2468-2481.

76 J. K. Tusa and H. He, J. Mater. Chem., 2005, 15, 2640-2647.

77 R. A. Tromans, T. S. Carter, L. Chabanne, M. P. Crump, H. Li, J. V. Matlock, M. G. Orchard and A. P. Davis, Nat. Chem., 2019, 11, 52-56.

78 M. Shamsipur, M. Hosseini, K. Alizadeh, N. Alizadeh, A. Yari, C. Caltagirone and V. Lippolis, Anal. Chim. Acta, 2005, 533, 17-24.

79 E. Biavardi, S. Federici, C. Tudisco, D. Menozzi, C. Massera, A. Sottini, G. G. Condorelli, P. Bergese and E. Dalcanale, Angew. Chem., Int. Ed., 2014, 53, 9183-9188.

80 D. Masseroni, E. Biavardi, D. Genovese, E. Rampazzo, L. Prodi and E. Dalcanale, Chem. Commun., 2015, 51, 12799-12802.

81 E. Biavardi, C. Tudisco, F. Maffei, A. Motta, C. Massera, G. G. Condorelli and E. Dalcanale, Proc. Natl. Acad. Sci. U. S. A., 2012, 109, 2263-2268.

82 G. Valenti, E. Rampazzo, E. Biavardi, E. Villani, G. Fracasso, M. Marcaccio, F. Bertani, D. Ramarli, E. Dalcanale, F. Paolucci and L. Prodi, Faraday Discuss., 2015, 185, 299-309.

83 G. Valenti, E. Rampazzo, S. Kesarkar, D. Genovese, A. Fiorani, A. Zanut, F. Palomba, M. Marcaccio, F. Paolucci and L. Prodi, Coord. Chem. Rev., 2018, 367, 65-81. 
84 L. You, J. S. Berman and E. V. Anslyn, Nat. Chem., 2011, 3, 943-948.

85 C. Di Natale, D. Monti and R. Paolesse, Mater. Today, 2010, 13, 46-52.

86 S. Erbas-Cakmak, D. A. Leigh, C. T. McTernan and A. L. Nussbaumer, Chem. Rev., 2015, 115, 10081-10206.

87 M. Stefanelli, G. Magna, F. Zurlo, F. M. Caso, E. Di Bartolomeo, S. Antonaroli, M. Venanzi, R. Paolesse, C. Di Natale and D. Monti, ACS Appl. Mater. Interfaces, 2019, 11, 12077-12087.

88 C. P. Montgomery, B. S. Murray, E. J. New, R. Pal and D. Parker, Acc. Chem. Res., 2009, 42, 925-937.

89 D. Parker, Chem. Soc. Rev., 2004, 33, 156-165.

90 D. Parker, R. S. Dickins, H. Puschmann, C. Crossland and J. A. K. Howard, Chem. Rev., 2002, 102, 1977-2010.

91 R. A. Poole, F. Kielar, S. L. Richardson, P. A. Stenson and D. Parker, Chem. Commun., 2006, 4084-4086.

92 B. D. Smith, Beilstein J. Org. Chem., 2015, 11, 2540-2548.

93 R. Pal, D. Parker and L. C. Costello, Org. Biomol. Chem., 2009, 7, 1525-1528.

94 B. A. Smith, W. J. Akers, W. M. Leevy, A. J. Lampkins, S. Xiao, W. Wolter, M. A. Suckow, S. Achilefu and B. D. Smith, J. Am. Chem. Soc., 2010, 132, 67-69.

95 A. Ojida, Y. Mito-Oka, M. A. Inoue and I. Hamachi, J. Am. Chem. Soc., 2002, 124, 6256-6258.

96 B. A. Smith, B. W. Xie, E. R. Van Beek, I. Que, V. Blankevoort, S. Xiao, E. L. Cole, M. Hoehn, E. L. Kaijzel, C. W. G. M. Löwik and B. D. Smith, ACS Chem. Neurosci., 2012, 3, 530-537.

97 E. Arunkumar, C. C. Forbes, B. C. Noll and B. D. Smith, J. Am. Chem. Soc., 2005, 127, 3288-3289.

98 E. Arunkumar, N. Fu and B. D. Smith, Chem. - Eur. J., 2006, 12, 4684-4690.

99 J. M. Dempsey, C. Zhai, H. H. McGarraugh, C. L. Schreiber, S. E. Stoffel, A. Johnson and B. D. Smith, Chem. Commun., 2019, 55, 12793-12796.

100 J. J. Gassensmith, J. M. Baumes and B. D. Smith, Chem. Commun., 2009, 6329-6338.

101 C. A. Daws, C. L. Exstrom, J. R. Sowa and K. R. Mann, Chem. Mater., 1997, 9, 363-368.

102 E. R. Li, K. C. Jie, M. Liu, X. R. Sheng, W. J. Zhu and F. H. Huang, Chem. Soc. Rev., 2020, 49, 1517-1544.

103 K. C. Jie, Y. J. Zhou, E. R. Li and F. H. Huang, Acc. Chem. Res., 2018, 51, 2064-2072.

104 E. R. Li, K. C. Jie, Y. J. Zhou, R. Zhao, B. Zhang, Q. Wang, J. Y. Liu and F. H. Huang, ACS Appl. Mater. Interfaces, 2018, 10, 23147-23153.

105 E. R. Li, K. C. Jie, Y. J. Zhou, R. Zhao and F. H. Huang, J. Am. Chem. Soc., 2018, 140, 15070-15079.

106 Q. Li, H. T. Z. Zhu and F. H. Huang, J. Am. Chem. Soc., 2019, 141, 13290-13294.

107 Y. J. Jang, K. Kim, O. G. Tsay, D. A. Atwood and D. G. Churchill, Chem. Rev., 2015, 115, PR1-PR76.

108 A. Barba-Bon, A. M. Costero, M. Parra, S. Gil, R. MartínezMáñez, F. Sancenõn, P. A. Gale and J. R. Hiscock, Chem. Eur. J., 2013, 19, 1586-1590.
109 J. R. Hiscock, N. J. Wells, J. A. Ede, P. A. Gale and M. R. Sambrook, Org. Biomol. Chem., 2016, 14, 9560-9567.

110 M. R. Sambrook, J. R. Hiscock, A. Cook, A. C. Green, I. Holden, J. C. Vincent and P. A. Gale, Chem. Commun., 2012, 48, 5605-5607.

111 J. R. Hiscock, I. L. Kirby, J. Herniman, G. John Langley, A. J. Clark and P. A. Gale, RSC Adv., 2014, 4, 45517-45521.

112 J. R. Hiscock, F. Piana, M. R. Sambrook, N. J. Wells, A. J. Clark, J. C. Vincent, N. Busschaert, R. C. D. Brown and P. A. Gale, Chem. Commun., 2013, 49, 9119-9121.

113 J. R. Hiscock, M. R. Sambrook, J. A. Ede, N. J. Wells and P. A. Gale, J. Mater. Chem. A, 2015, 3, 1230-1234.

114 J. R. Hiscock, M. R. Sambrook, N. J. Wells and P. A. Gale, Chem. Sci., 2015, 6, 5680-5684.

115 F. Piana, M. Facciotti, G. Pileio, J. R. Hiscock, W. Van Rossom, R. C. D. Brown and P. A. Gale, RSC Adv., 2015, 5, 12287-12292.

116 N. A. Esipenko, P. Koutnik, T. Minami, L. Mosca, V. M. Lynch, G. V. Zyryanov and P. Anzenbacher, Chem. Sci., 2013, 4, 3617-3623.

117 A. Barba-Bon, A. M. Costero, S. Gil, R. Martínez-Máñez and F. Sancenón, Org. Biomol. Chem., 2014, 12, 8745-8751.

118 J. R. Hiscock, G. P. Bustone and E. R. Clark, ChemistryOpen, 2017, 6, 497-500.

119 Y. Kalinovskyy, A. J. Wright, J. R. Hiscock, T. D. Watts, R. L. Williams, N. J. Cooper, M. J. Main, S. J. Holder and B. A. Blight, ACS Appl. Mater. Interfaces, 2020, 12, 8634-8641.

120 A. J. Wright, M. J. Main, N. J. Cooper, B. A. Blight and S. J. Holder, ACS Appl. Mater. Interfaces, 2017, 9, 31335-31339.

121 Y. Kalinovskyy, N. J. Cooper, M. J. Main, S. J. Holder and B. A. Blight, Dalton Trans., 2017, 46, 15704-15709.

122 A. M. Wilson, P. J. Bailey, P. A. Tasker, J. R. Turkington, R. A. Grant and J. B. Love, Chem. Soc. Rev., 2014, 43, 123-134.

123 J. R. Turkington, P. J. Bailey, J. B. Love, A. M. Wilson and P. A. Tasker, Chem. Commun., 2013, 49, 1891-1899.

124 G. A. Kordosky, presented in part at the 18th International Solvent Extraction Conference, Cape Town, South Africa, 2002.

125 IBC Advanced Technologies, Inc., http://www.ibcmrt.com/, (accessed 29/10/2020).

126 D. D. Walker, M. A. Norato, S. G. Campbell, M. L. Crowder, S. D. Fink, F. F. Fondeur, M. W. Geeting, G. F. Kessinger and R. A. Pierce, Sep. Sci. Technol., 2005, 40, 297-309.

127 R. M. Izatt, Chem. Eng. Prog., 2015, 111, 48-54.

128 J. J. M. Nelson and E. J. Schelter, Inorg. Chem., 2019, 58, 979-990.

129 M. D. Rao, K. K. Singh, C. A. Morrison and J. B. Love, $R S C$ $A d v .$, 2020, 10, 4300-4309.

130 C. Hagelüken and C. W. Corti, Gold Bull., 2010, 43, 209-220.

131 A. Greenfield and T. E. Graedel, Resour., Conserv. Recycl., 2013, 74, 1-7.

132 Z. Liu, M. Frasconi, J. Lei, Z. J. Brown, Z. Zhu, D. Cao, J. Iehl, G. Liu, A. C. Fahrenbach, Y. Y. Botros, O. K. Farha, 
J. T. Hupp, C. A. Mirkin and J. Fraser Stoddart, Nat. Commun., 2013, 4, 1855.

133 cycladex, http://cycladex.com/, (accessed 29/10/2020).

134 R. B. Pettman and D. F. Arnolds, US Pat., WO2017158561A1, 2017.

135 FS ventures, https://www.fs-ventures.co.uk/investee-companies/ investee-companies/cycladex-ltd/, accessed 29/10/2020.

136 L. X. Chen, M. Liu, Y. Q. Zhang, Q. J. Zhu, J. X. Liu, B. X. Zhu and Z. Tao, Chem. Commun., 2019, 55, 14271-14274.

137 R.-L. Lin, Y.-P. Dong, M. Tang, Z. Liu, Z. Tao and J.-X. Liu, Inorg. Chem., 2020, 59, 3850-3855.

138 H. Wu, L. O. Jones, Y. Wang, D. Shen, Z. Liu, L. Zhang, K. Cai, Y. Jiao, C. L. Stern, G. C. Schatz and J. F. Stoddart, ACS Appl. Mater. Interfaces, 2020, 12, 38768-38777.

139 Z. Liu, A. Samanta, J. Lei, J. Sun, Y. Wang and J. F. Stoddart, J. Am. Chem. Soc., 2016, 138, 11643-11653.

140 E. D. Doidge, I. Carson, P. A. Tasker, R. J. Ellis, C. A. Morrison and J. B. Love, Angew. Chem., Int. Ed., 2016, 55, 12436-12439.

141 E. D. Doidge, L. M. M. Kinsman, Y. Ji, I. Carson, A. J. Duffy, I. A. Kordas, E. Shao, P. A. Tasker, B. T. Ngwenya, C. A. Morrison and J. B. Love, ACS Sustainable Chem. Eng., 2019, 7, 15019-15029.

142 J. E. Tamis, R. H. Jongbloed, C. C. Karman, W. Koops and A. J. Murk, Integr. Environ. Assess. Manage., 2012, 8, 231-241.

143 A. M. Vibhute and K. M. Sureshan, ChemSusChem, 2020, 13, 5343-5360.

144 D. P. O'Mara, A. F. Hadermann and J. C. Trippe, US Pat., US4720397A, 1988.

145 B. Doshi, M. Sillanpää and S. Kalliola, Water Res., 2018, 135, 262-277.

146 B. O. Okesola and D. K. Smith, Chem. Soc. Rev., 2016, 45, 4226-4251.

147 T. Kobayashi, Y. Kawashima, M. Yoshimura, M. Sugiura, T. Nobe and S. Fujimoto, US Pat., 4502975, 1985.

148 R. G. Weiss and A. M. V. Mallya, Worldwide Pat., WO2012047251A1, 2012.

149 B. Zhang, S. Chen, H. Luo, B. Zhang, F. Wang and J. Song, J. Hazard. Mater., 2020, 384, 121460.

150 R. P. Schwarzenbach, B. I. Escher, K. Fenner, T. B. Hofstetter, C. A. Johnson, U. von Gunten and B. Wehrli, Science, 2006, 313, 1072-1077.

151 A. Alsbaiee, B. J. Smith, L. L. Xiao, Y. H. Ling, D. E. Helbling and W. R. Dichtel, Nature, 2016, 529, 190-194.

152 B. A. Moyer, R. Custelcean, B. P. Hay, J. L. Sessler, K. Bowman-James, V. W. Day and S.-O. Kang, Inorg. Chem., 2013, 52, 3473-3490.

153 R. Custelcean, N. J. Williams and C. A. Seipp, Angew. Chem., Int. Ed., 2015, 54, 10525-10529.

154 R. Custelcean, N. J. Williams, C. A. Seipp, A. S. Ivanov and V. S. Bryantsev, Chem. - Eur. J., 2016, 22, 1997-2003.

155 C. A. Seipp, N. J. Williams, V. S. Bryantsev, R. Custelcean and B. A. Moyer, RSC Adv., 2015, 5, 107266-107269.

156 L. Qin, S. J. N. Vervuurt, R. B. P. Elmes, S. N. Berry, N. Proschogo and K. A. Jolliffe, Chem. Sci., 2020, 11, 201-207.
157 J. L. Humphrey, Separation process technology, McGrawHill, New York, London, 1997.

158 D. S. Sholl and R. P. Lively, Nature, 2016, 533, 316.

159 X. Zhao, Y. Wang, D.-S. Li, X. Bu and P. Feng, Adv. Mater., 2018, 30, 1705189.

160 Z. F. Wang, S. N. Zhang, Y. Chen, Z. J. Zhang and S. Q. Ma, Chem. Soc. Rev., 2020, 49, 708-735.

161 M. Mofarahi and F. Gholipour, Microporous Mesoporous Mater., 2014, 200, 1-10.

162 E. J. Garcia, J. Perez-Pellitero, G. D. Pirngruber, C. Jallut, M. Palomino, F. Rey and S. Valencia, Ind. Eng. Chem. Res., 2014, 53, 9860-9874.

163 M. Yu, R. D. Noble and J. L. Falconer, Acc. Chem. Res., 2011, 44, 1196-1206.

164 J. R. Wu and Y. W. Yang, Angew. Chem., Int. Ed., 2020, DOI: 10.1002/anie.202006999.

165 K. C. Jie, M. Liu, Y. J. Zhou, M. A. Little, S. Bonakala, S. Y. Chong, A. Stephenson, L. J. Chen, F. H. Huang and A. I. Cooper, J. Am. Chem. Soc., 2017, 139, 2908-2911.

166 X. G. Li, C. T. Cui, H. Li and X. Gao, Sep. Purif. Technol., 2019, 228, 10.

167 H. M. V. Tassel, US Pat., US3398063A, 1966.

168 K. C. Jie, M. Liu, Y. J. Zhou, M. A. Little, A. Pulido, S. Y. Chong, A. Stephenson, A. R. Hughes, F. Sakakibara, T. Ogoshi, F. Blanc, G. M. Day, F. H. Huang and A. I. Cooper, J. Am. Chem. Soc., 2018, 140, 6921-6930.

169 G. Zhang, B. Moosa, A. Chen and N. M. Khashab, ChemPlusChem, 2020, 85, 1244-1248.

170 Y. J. Zhou, K. C. Jie, R. Zhao, E. R. Li and F. H. Huang, J. Am. Chem. Soc., 2020, 142, 6957-6961.

171 D. Cantillo and C. O. Kappe, React. Chem. Eng., 2017, 2, 7-19.

172 J. R. Wu, A. U. Mu, B. Li, C. Y. Wang, L. Fang and Y. W. Yang, Angew. Chem., Int. Ed., 2018, 57, 9853-9858.

173 J. R. Wu, B. Li and Y. W. Yang, Angew. Chem., Int. Ed., 2020, 59, 2251-2255.

174 Q. Li, K. C. Jie and F. H. Huang, Angew. Chem., Int. Ed., 2020, 59, 5355-5358.

175 Y. Li, W. S. Li, L. Zhong and C. J. Xu, Ind. Eng. Chem. Res., 2017, 56, 11894-11902.

176 D. B. Amabilino, D. K. Smith and J. W. Steed, Chem. Soc. Rev., 2017, 46, 2404-2420.

177 X. Z. Yan, F. Wang, B. Zheng and F. H. Huang, Chem. Soc. Rev., 2012, 41, 6042-6065.

178 V. R. de la Rosa, P. Woisel and R. Hoogenboom, Mater. Today, 2016, 19, 44-55.

179 A. Lavrenova, D. W. R. Balkenende, Y. Sagara, S. Schrettl, Y. C. Simon and C. Weder, J. Am. Chem. Soc., 2017, 139, 4302-4305.

180 B. Y. Xia, B. Zheng, C. Y. Han, S. Y. Dong, M. M. Zhang, B. J. Hu, Y. H. Yu and F. H. Huang, Polym. Chem., 2013, 4, 2019-2024.

181 I. Yoshimura, Y. Miyahara, N. Kasagi, H. Yamane, A. Ojida and I. Hamachi, J. Am. Chem. Soc., 2004, 126, 12204-12205.

182 M. Ikeda, K. Fukuda, T. Tanida, T. Yoshii and I. Hamachi, Chem. Commun., 2012, 48, 2716-2718. 
183 L. L. Yang, X. X. Tan, Z. Q. Wang and X. Zhang, Chem. Rev., 2015, 115, 7196-7239.

184 L. Brunsveld, B. J. B. Folmer, E. W. Meijer and R. P. Sijbesma, Chem. Rev., 2001, 101, 4071-4098.

185 D. G. Bekas, K. Tsirka, D. Baltzis and A. S. Paipetis, Composites, Part B, 2016, 87, 92-119.

186 N. J. Kanu, E. Gupta, U. K. Vates and G. K. Singh, Composites, Part A, 2019, 121, 474-486.

187 V. V. Kumar, G. Balaganesan, J. K. Y. Lee, R. E. Neisiany, S. Surendran and S. Ramakrishna, Polymers, 2019, 11, 19.

188 Y. J. Wang, D. T. Pham and C. Q. Ji, Cogent Eng., 2015, 2, 28.

189 F. Behzad, N. Navid and D. Amir, J. Manuf. Mater. Process., 2019, 3, 28.

190 F. M. Raymo and J. F. Stoddart, Chem. Rev., 1999, 99, 1643-1663.

191 J. F. Stoddart, Angew. Chem., Int. Ed., 2017, 56, 11094-11125. 192 L. Fang, M. A. Olson, D. Benitez, E. Tkatchouk, W. A. Goddard and J. F. Stoddart, Chem. Soc. Rev., 2010, 39, 17-29.

193 T. Takata, Polym. J., 2006, 38, 1-20.

194 A. W. Heard and S. M. Goldur, ACS Cent. Sci., 2020, 6, 117-128.

195 Y. H. Jin, C. Yu, R. J. Denman and W. Zhang, Chem. Soc. Rev., 2013, 42, 6634-6654.

196 G. M. Peters, X. D. Chi, C. Brockman and J. L. Sessler, Chem. Commun., 2018, 54, 5407-5409.

197 https://www.globenewswire.com/news-release/2020/02/12/ 1983950/0/en/Industrial-Rubber-Market-to-Garner-44-6Billion-by-2026-Allied-Market-Research.html, (accessed 05/06/2020).

198 A. Das, A. Sallat, F. Bohme, M. Suckow, D. Basu, S. Wiessner, K. W. Stockelhuber, B. Voit and G. Heinrich, ACS Appl. Mater. Interfaces, 2015, 7, 20623-20630.

199 Z. L. Yu, F. Tantakitti, T. Yu, L. C. Palmer, G. C. Schatz and S. I. Stupp, Science, 2016, 351, 497-502.

200 X. H. Zhao, Soft Matter, 2014, 10, 672-687.

201 J. Kruzelak, R. Sykora and I. Hudec, Chem. Pap., 2016, 70, 1533-1555.

202 M. Suckow, A. Mordvinkin, M. Roy, N. K. Singha, G. Heinrich, B. Voit, K. Saalwachter and F. Bohme, Macromolecules, 2018, 51, 468-479.

203 L. Landini, S. G. de Araujo, A. B. Lugao and H. Wiebeck, Eur. Polym. J., 2007, 43, 2725-2731.

204 S. Stein, A. Mordvinkin, B. Voit, H. Komber, K. Saalwachter and F. Bohme, Polym. Chem., 2020, 11, 1188-1197.
205 Y. Ahn, Y. Jang, N. Selvapalam, G. Yun and K. Kim, Angew. Chem., Int. Ed., 2013, 52, 3140-3144.

206 R. J. Stewart, T. C. Ransom and V. Hlady, J. Polym. Sci., Part B: Polym. Phys., 2011, 49, 757-771.

207 H. Shao and R. J. Stewart, Adv. Mater., 2010, 22, 729.

208 R. Santos, G. da Costa, C. Franco, P. Gomes-Alves, P. Flammang and A. V. Coelho, Mar. Biotechnol., 2009, 11, 686-698.

209 M. A. North, C. A. Del Grosso and J. J. Wilker, ACS Appl. Mater. Interfaces, 2017, 9, 7866-7872.

210 X. Y. Sha, C. X. Zhang, M. W. Qi, L. H. Zheng, B. K. Cai, F. Chen, Y. L. Wang and Y. F. Zhou, Macromol. Rapid Commun., 2020, 41, 2000055.

211 W. Zhang, R. X. Wang, Z. M. Sun, X. W. Zhu, Q. Zhao, T. F. Zhang, A. Cholewinski, F. Yang, B. X. Zhao, R. Pinnaratip, P. K. Forooshani and B. P. Lee, Chem. Soc. Rev., 2020, 49, 433-464.

212 A. H. Hofman, I. A. van Hees, J. Yang and M. Kamperman, Adv. Mater., 2018, 30, 38.

213 Q. Guo, J. S. Chen, J. L. Wang, H. B. Zeng and J. Yu, Nanoscale, 2020, 12, 1307-1324.

214 M. H. Lauren and J. J. Wilker, J. Mater. Sci., 2007, 42, 8934-8942.

215 Q. H. Wang, Y. L. Zhong, D. P. Miller, X. X. Lu, Q. Tang, Z. L. Lu, E. Zurek, R. Liu and B. Gong, J. Am. Chem. Soc., 2020, 142, 2915-2924.

216 K. Kim, N. Selvapalam, Y. H. Ko, K. M. Park, D. Kim and J. Kim, Chem. Soc. Rev., 2007, 36, 267-279.

217 G. Westwood, T. N. Horton and J. J. Wilker, Macromolecules, 2007, 40, 3960-3964.

218 M. E. Yu and T. J. Deming, Macromolecules, 1998, 31, 4739-4745.

219 D. Sobransingh and A. E. Kaifer, Org. Lett., 2006, 8, 3247-3250.

220 J. Courtois, I. Baroudi, N. Nouvel, E. Degrandi, S. Pensec, G. Ducouret, C. Chaneac, L. Bouteiller and C. Creton, $A d v$. Funct. Mater., 2010, 20, 1803-1811.

221 X. Li, Y. Deng, J. L. Lai, G. Zhao and S. Y. Dong, J. Am. Chem. Soc., 2020, 142, 5371-5379.

222 I. Kovalenko, B. Zdyrko, A. Magasinski, B. Hertzberg, Z. Milicev, R. Burtovyy, I. Luzinov and G. Yushin, Science, 2011, 334, 75-79.

223 S. Choi, T. W. Kwon, A. Coskun and J. W. Choi, Science, 2017, 357, 279-283. 